\title{
Estimating Water Storage Capacity of Existing and Potentially Restorable Wetland Depressions in a Subbasin of the Red River of the North
}

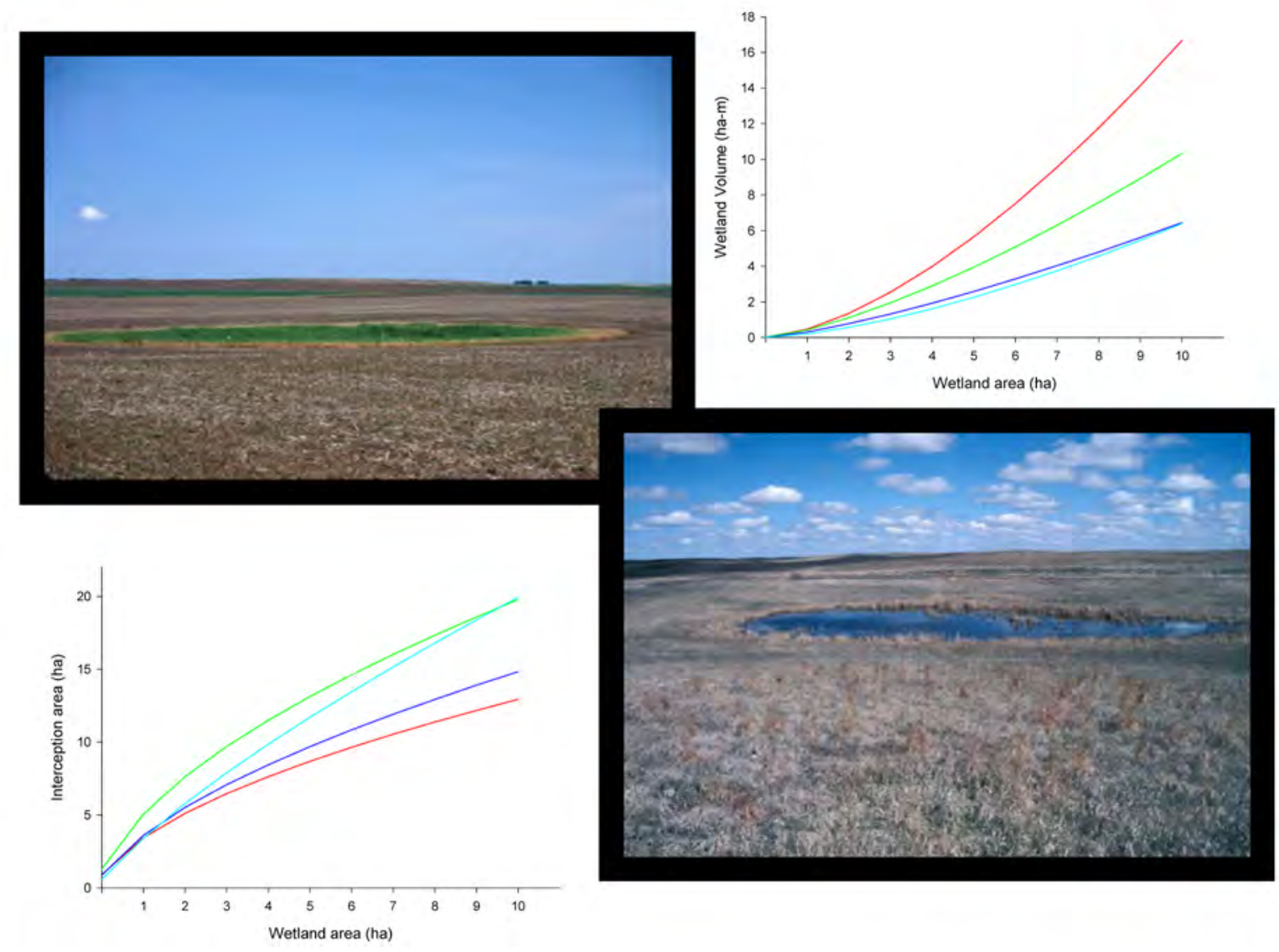

Open-File Report 2007-1159 
Front cover photographs: Upper left, seasonal wetland surrounded by cropland; lower right, seasonal wetland surrounded by restored grassland. 


\section{Estimating Water Storage Capacity of Existing and Potentially Restorable Wetland Depressions in a Subbasin of the Red River of the North}

By Robert A. Gleason, Brian A. Tangen, Murray K. Laubhan, Kevin E. Kermes, and Ned H. Euliss, Jr.

Open-File Report 2007-1159 


\section{U.S. Department of the Interior DIRK KEMPTHORNE, Secretary}

\section{U.S. Geological Survey \\ Mark D. Myers, Director}

\section{U.S. Geological Survey, Reston, Virginia: 2007}

For product and ordering information:

World Wide Web: http://www.usgs.gov/pubprod

Telephone: 1-888-ASK-USGS

For more information on the USGS--the Federal source for science about the Earth, its natural and living resources, natural hazards, and the environment:

World Wide Web: http://www.usgs.gov

Telephone: 1-888-ASK-USGS

Any use of trade, product, or firm names is for descriptive purposes only and does not imply endorsement by the U.S. Government.

Although this report is in the public domain, permission must be secured from the individual copyright owners to reproduce any copyrighted materials contained within this report.

Suggested citation:

Gleason, R.A., Tangen, B.A., Laubhan, M.K., Kermes, K.E., and Euliss, N.H., Jr., 2007, Estimating water storage capacity of existing and potentially restorable wetland depressions in a subbasin of the Red River of the North: U.S. Geological Survey Open-File Report 2007-1159, 36 p. 


\section{Contents}

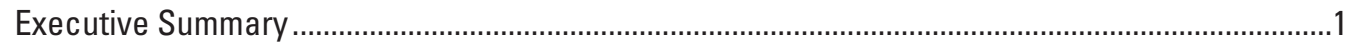

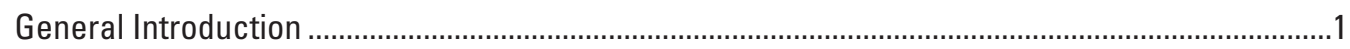

Chapter A: Development of Wetland Volume and Interception Area Estimators ..............................

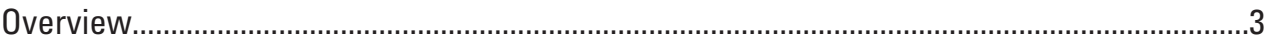

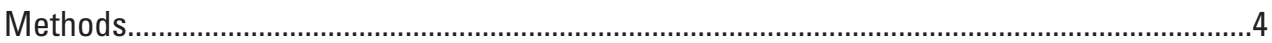

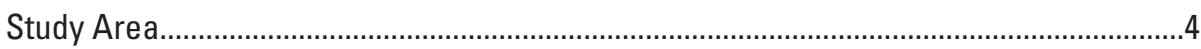

Topographic Surveys ............................................................................................

Statistical Analyses/Model Development ……………..............................................

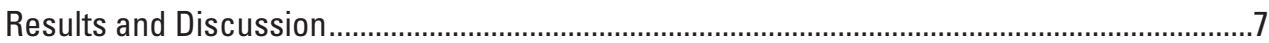

Evaluation of Surface Area to Volume Relationships ........................................................

Evaluation of Surface Area to Interception Area Relationships........................................8

Estimating Depressional Storage and Interception Areas ................................................11

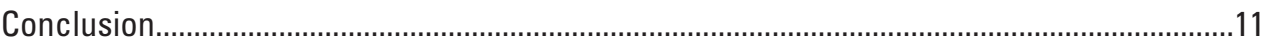

Chapter B: Wetland Water Storage Simulation Model ...............................................................14

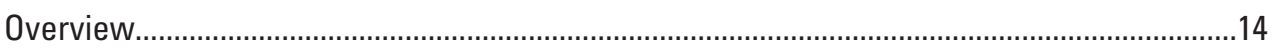

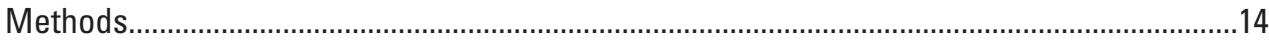

Model Development/Assumptions........................................................................14

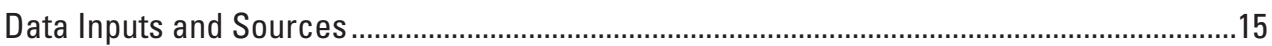

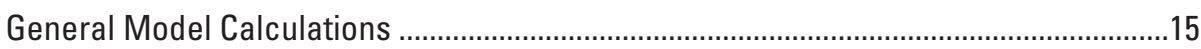

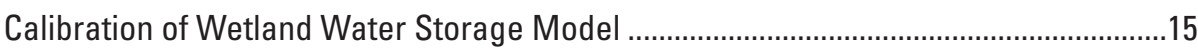

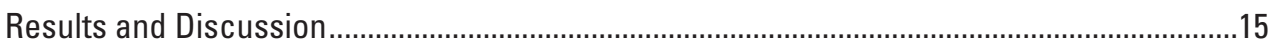

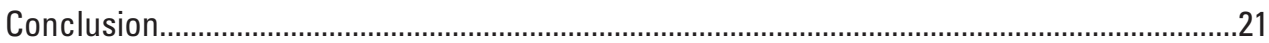

Chapter C: Application of the Wetland Water Storage Simulation Model to the

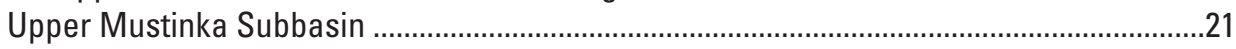

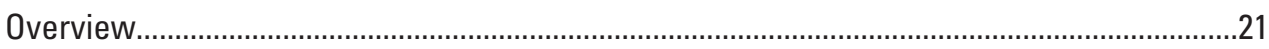

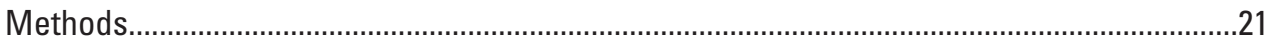

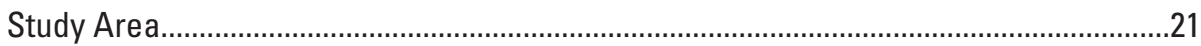

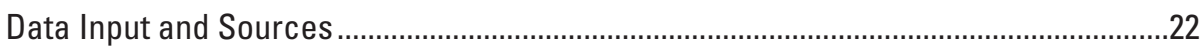

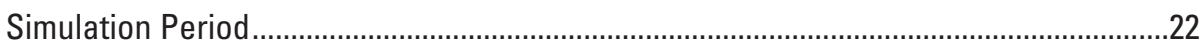

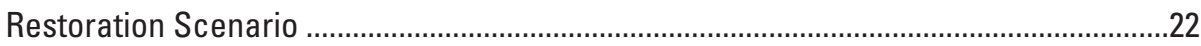

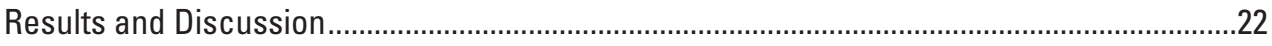

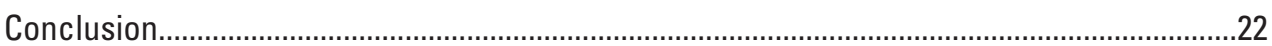

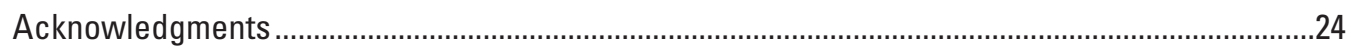

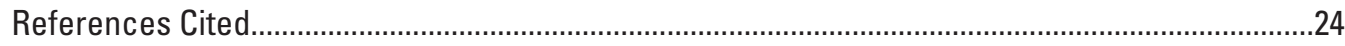

Appendix 1. Acquiring input data, defining model scenarios, obtaining runoff curve numbers, creating input database, and interpreting model simulations .............................28

Appendix 2. SAS program to create input database for simulation model ...................................31

Appendix 3. SAS program for simulation model ........................................................................32

Appendix 4. Description of SAS code used to create input database for simulation

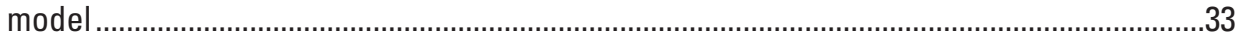

Appendix 5. Description of SAS code for simulation model ........................................................

Appendix 6. SAS program used to create input database for 1987 simulation model..................35

Appendix 7. SAS program for 1987 (25 percent restoration scenario) simulation model ............36 


\section{Figures}

1-3. Maps showing:

1. Area of major river drainage basins and physiographic regions within the Prairie Pothole Region of the United States.

2. Location of sections $(1.6 \times 1.6 \mathrm{~km})$ where wetlands were surveyed in the upper Mustinka subbasin within Grant County, Minn. .4

3. National Wetlands Inventory and Restorable Wetlands Working Group wetland data for the upper Mustinka subbasin within Grant County, Minn. .5

4. Plan and profile view of wetland and catchment areas as defined in this report.............6

5. Representation of a typical spatial distribution of wetlands and catchments throughout a landscape.

6-9. Graphs showing:

6. Comparison of surface area-volume relationships among the model developed for the upper Mustinka subbasin and models for the three physiographic regions of the Prairie Pothole Region

7. Relationship between 123 wetland surface areas obtained from the National Wetlands Inventory and areas for the same sites obtained from ground-based topographic surveys

8. Comparison of surface area-interception area relationships among the model developed for the upper Mustinka subbasin and models for the three physiographic regions of the Prairie Pothole Region

9. Catchment area-wetland area ratios (catchment area/wetland area) relative to wetland size

10-11. Maps showing:

10. Total storage volumes $($ ha-m) per hectare per section $(1.6 \times 1.6 \mathrm{~km})$ in the upper Mustinka subbasin of Grant County, Minn.

11. Percentage of section $(1.6 \times 1.6 \mathrm{~km})$ area covered by interception areas .............13

12. Diagram showing catchment and wetland zones used in wetland water storage simulation model

13. Graphs showing simulation model calibration for the Cottonwood Lake study area wetlands for the time period of April 14 to September 21, 1993. 


\section{Tables}

1. Predictive models developed for restorable wetlands in the upper Mustinka subbasin of Grant County, Minn. (data from this study), and the three physiographic regions of the Prairie Pothole Region.

2. Maximum storage volumes and interception areas of existing and potentially restorable wetlands in the upper Mustinka subbasin of Grant County, Minn.

3. Precipitation events used in the calibration of the simulation model for the time period of April 14 to September 21, 1993

4. Results from model simulations performed on National Wetlands Inventory and Restorable Wetlands Working Group wetland data for the upper Mustinka subbasin of Grant County, Minn., for the growing seasons of 1987 and 1993

5. Percent of total precipitation stored by depressional wetlands in the upper Mustinka subbasin of Grant County, Minn.

1-1. Definition of input database variables for simulation model........................................29

1-2. Definition of variables created in the wetland hydrology simulation model......

\section{Conversion Factors}

Inch/Pound to SI

\begin{tabular}{lll}
\hline Multiply & By & To obtain \\
\hline inch (in.) & Length & \\
foot (ft) & 2.54 & centimeter (cm) \\
mile (mi) & 0.3048 & meter (m) \\
\hline & 1.609 & kilometer (km) \\
\hline acre & Area & hectare (ha) \\
\hline & 0.4047 & \\
\hline acre-foot (acre-ft) & Volume & hectare (ha) \\
\hline
\end{tabular}

SI to Inch/Pound

\begin{tabular}{lcl}
\hline Multiply & By & To obtain \\
\hline & Length & \\
\hline centimeter $(\mathrm{cm})$ & 0.3937 & inch (in.) \\
meter $(\mathrm{m})$ & 3.281 & foot (ft) \\
kilometer $(\mathrm{km})$ & 0.6214 & mile (mi) \\
\hline & Area & acre \\
\hline hectare (ha) & 2.471 & \\
\hline hectare-meters (ha-m) & Volume & acre-foot (acre-ft) \\
\hline
\end{tabular}




\title{
Estimating Water Storage Capacity of Existing and Potentially Restorable Wetland Depressions in a Subbasin of the Red River of the North
}

\author{
By Robert A. Gleason, Brian A. Tangen, Murray K. Laubhan, Kevin E. Kermes, and Ned H. Euliss, Jr.
}

\section{Executive Summary}

Concern over flooding along rivers in the Prairie Pothole Region has stimulated interest in developing spatially distributed hydrologic models to simulate the effects of wetland water storage on peak river flows. Such models require spatial data on the storage volume and interception area of existing and restorable wetlands in the watershed of interest. In most cases, information on these model inputs is lacking because resolution of existing topographic maps is inadequate to estimate volume and areas of existing and restorable wetlands. Consequently, most studies have relied on wetland area to volume or interception area relationships to estimate wetland basin storage characteristics by using available surface area data obtained as a product from remotely sensed data (e.g., National Wetlands Inventory). Though application of areal input data to estimate volume and interception areas is widely used, a drawback is that there is little information available to provide guidance regarding the application, limitations, and biases associated with such approaches. Another limitation of previous modeling efforts is that water stored by wetlands within a watershed is treated as a simple lump storage component that is filled prior to routing overflow to a pour point or gaging station. This approach does not account for dynamic wetland processes that influence water stored in prairie wetlands. Further, most models have not considered the influence of human-induced hydrologic changes, such as land use, that greatly influence quantity of surface water inputs and, ultimately, the rate that a wetland basin fills and spills.

The goals of this study were to (1) develop and improve methodologies for estimating and spatially depicting wetland storage volumes and interceptions areas and (2) develop models and approaches for estimating/simulating the water storage capacity of potentially restorable and existing wetlands under various restoration, land use, and climatic scenarios. To address these goals, we developed models and approaches to spatially represent storage volumes and interception areas of existing and potentially restorable wetlands in the upper Mustinka subbasin within Grant County, Minn. We then developed and applied a model to simulate wetland water storage increases that would result from restoring 25 and
50 percent of the farmed and drained wetlands in the upper Mustinka subbasin. The model simulations were performed during the growing season (May-October) for relatively wet (1993; $0.67 \mathrm{~m}$ of precipitation) and dry (1987; $0.32 \mathrm{~m}$ of precipitation) years. Results from the simulations indicated that the 25 percent restoration scenario would increase water storage by $27-32$ percent and that a 50 percent scenario would increase storage by 53-63 percent. Additionally, we estimated that wetlands in the subbasin have potential to store 11.57-20.98 percent of the total precipitation that fell over the entire subbasin area (52,758 ha). Our simulation results indicated that there is considerable potential to enhance water storage in the subbasin; however, evaluation and calibration of the model is necessary before simulation results can be applied to management and planning decisions.

In this report we present guidance for the development and application of models (e.g., surface area-volume predictive models, hydrology simulation model) to simulate wetland water storage to provide a basis from which to understand and predict the effects of natural or human-induced hydrologic alterations. In developing these approaches, we tried to use simple and widely available input data to simulate wetland hydrology and predict wetland water storage for a specific precipitation event or a series of events. Further, the hydrology simulation model accounted for land use and soil type, which influence surface water inputs to wetlands. Although information presented in this report is specific to the Mustinka subbasin, the approaches and methods developed should be applicable to other regions in the Prairie Pothole Region.

\section{General Introduction}

The Prairie Pothole Region of the northern Great Plains encompasses a large portion of major river drainage basins including the Red of the North, Missouri, and Mississippi Rivers (fig. 1). In recent years, the magnitude and frequency of flooding in these drainage basins have caused concern that land use changes and wetland drainage have increased flooding (Brun and others, 1981; Miller and Frink, 1984; Miller and Nudds, 1995; Manale, 2000). Most notable is flooding 
along the Red River of the North that in recent years has caused enormous economic losses and inflicted serious social hardships. Most of the Red River of the North basin has been intensively farmed, and over 50 percent of the wetlands have been drained (Tiner, 1984; Dahl, 1990; Dahl and Johnson, 1991). Wetland depressions are important landscape features of river drainages in the Prairie Pothole Region, and alteration of wetlands (e.g., draining, changing land use in watershed) has been implicated with increases in the frequency and magnitude of flood events (Brun and others, 1981; Miller and Nudds, 1995). Consequently, flooding along rivers in the Prairie Pothole Region has stimulated much interest in developing spatially distributed hydrologic models to simulate the effects of wetland water storage on peak river flows (Moore and Larson, 1979; Bengtson and Padmanabhan, 1999; Simonovic and Juliano, 2001; Vining, 2002).

Attempts to model the impact of wetland water stores on peak river flows are often constrained by lack of information on wetland volumes and interception areas. Estimating wetland volumes in the Prairie Pothole Region is problematic because resolution of available databases (e.g., topographic and digital elevation maps) is inadequate to estimate depressional volumes. Given these constraints, modeling efforts generally have estimated wetland volumes by applying models available in the literature that capture definable relationships between volume and wetland surface area (Haan and Johnson, 1967; Best, 1978; Best and Moore, 1979; Hubbard, 1982; Bell and others, 1999; Bengtson and Padmanabhan, 1999; Wiens, 2001). These models are applied to available wetland surface area data (e.g., National Wetlands Inventory (NWI)) to estimate storage volumes. Though this approach is frequently used, definable relationships between volume and wetland surface area vary throughout the Prairie Pothole Region. For example, the Prairie Pothole Region consists of three primary physiographic regions, the Glaciated Plains, Missouri Coteau, and Prairie Coteau (fig. 1) that differ greatly in landform (e.g., ground moraine, dead-ice moraine (Bluemle 2000)) and, consequently, in topographic relief. Morphological variations between these regions result in differences in wetland surface area and volume relationships (Hubbard, 1982). Given these topographic differences, models developed to predict wetland volumes in one landform may not work well in a different landform. Currently, there is little information available to provide guidance regarding the application and biases associated with such approaches. Similarly, there is little information available when using comparable approaches to estimate wetland interception areas. Here, we define interception area as the area of the wetland plus the area of the upland catchment

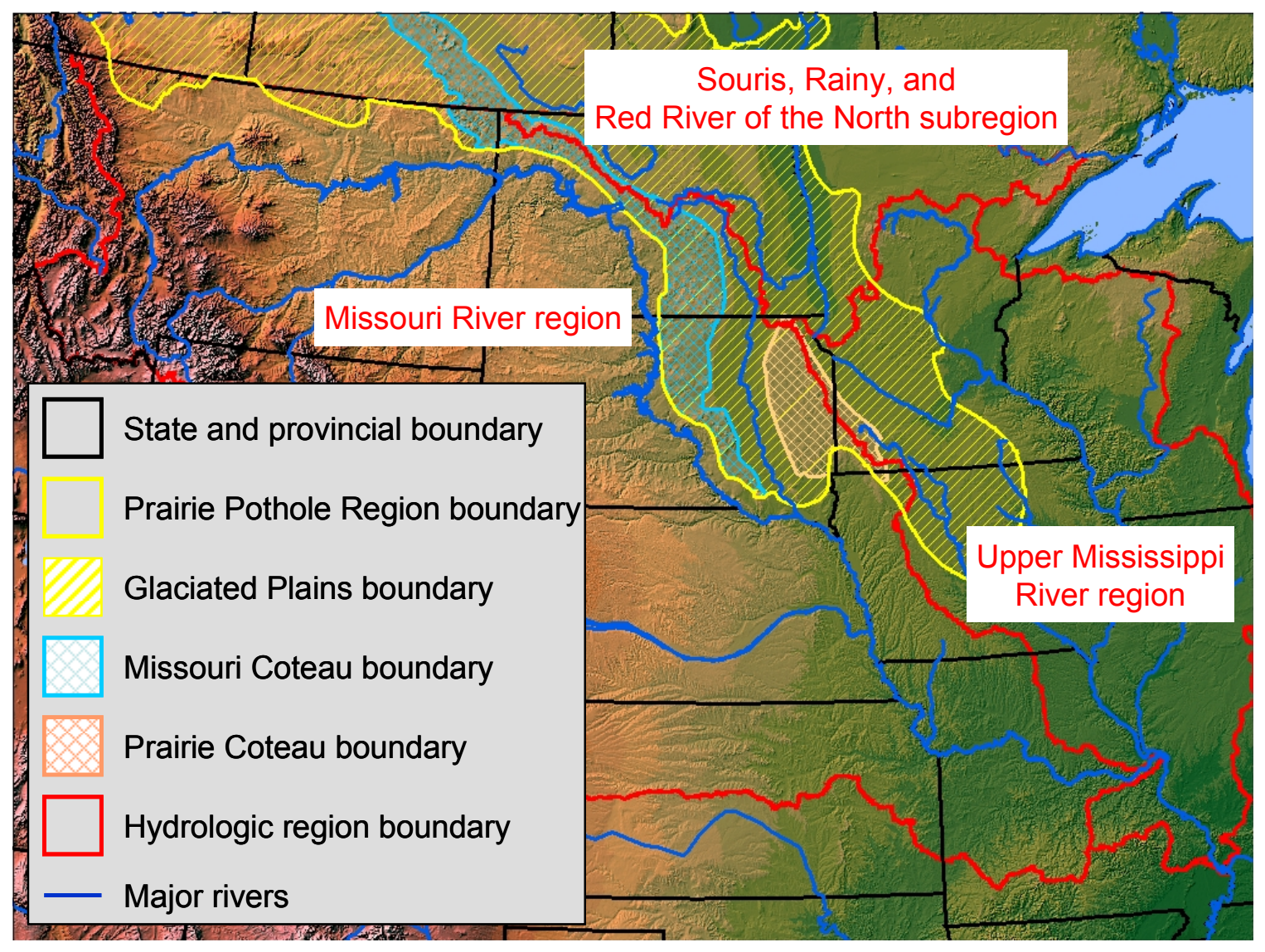

Figure 1. Area of major river drainage basins and physiographic regions within the Prairie Pothole Region of the United States. 
or contributing area. Interception area is an important model component because it accounts for areas in the watershed that do not route water directly to ditches or streams.

Another limitation of previous modeling efforts is that water stored by wetlands within a watershed is treated as a simple lump storage component that is filled before overflow is routed to a pour point or gaging station. This approach does not account for dynamic wetland processes that influence water stored in prairie wetlands. Further, most models have not considered the influence of human-induced hydrologic changes, such as land use, that greatly influence quantity of surface water inputs and, ultimately, the rate that wetland basins fill and spill. In this report we rely on the conceptual model that the primary sources of water for Prairie Pothole Region wetlands are direct precipitation and surface runoff from the catchment (i.e., area contributing surface runoff to a wetland basin), which is highly influenced by land use (e.g., grassland, cropland). The primary sources of water loss are evapotranspiration and surface outflow (i.e., overflow) when a wetland basin is filled beyond capacity. We consider two types of wetland water storage, existing and potential. Existing refers to the capacity of existing wetlands to store water, and potential refers to the capacity of restorable wetlands to store water. Existing wetlands are defined as intact, palustrine wetlands identified by the NWI, and potentially restorable wetlands are drained wetlands in agricultural landscapes mapped by the Restorable Wetlands Working Group (RWWG; 2002). The storage potential of the drained wetlands is based on the premise that the wetland hydrology is restored by plugging surface drains, breaking drainage tile, etc.

The goals of this study were to (1) develop and improve methodologies for estimating and spatially depicting wetland storage volume and interception areas and (2) develop models and approaches for simulating water storage capacity of potentially restorable and existing wetlands under various restoration, land use, and climatic scenarios. To address these goals, we focused our work on the upper Mustinka subbasin located in Grant County, Minn. This subbasin was selected because of the availability of a geographic information systems database that identifies restorable wetlands (Restorable Wetlands Working Group, 2002) that are otherwise not accounted for in traditional wetland databases (e.g., NWI). Although information presented in this report is specific to this subbasin, the approaches and methods used can be applied to other regions in the Prairie Pothole Region.

This report is organized into three primary chapters. In chapter A, we develop wetland volume and interception area models to estimate maximum storage potential and interception area of existing and potentially restorable wetlands in the upper Mustinka subbasin. In chapter B, we develop a wetland water storage simulation model that can be used for simulating various restoration, land use, and climatic scenarios. Lastly, in chapter $\mathrm{C}$, we apply models developed in chapters A and B to simulate the impact of wetland restoration scenarios on water storage in the upper Mustinka subbasin. Each chapter consists of Overview, Methods, Results and Discussion, and Conclusion sections. Chapters do not include an introduction; rather, the Overview - which includes a brief statement of the problem, goals, approach to solve the problem, and relevant findings - is intended to serve this purpose.

\section{Chapter A: Development of Wetland Volume and Interception Area Estimators}

\section{Overview}

Flooding along rivers in the Prairie Pothole Region has stimulated interest in developing spatially distributed hydrologic models to simulate the effects of wetland water storage on peak river flows. Such models require spatial data on the storage volumes and interception areas of existing and restorable wetlands in the watershed of interest; however, spatially distributed hydrologic models often rely on areal input data from geographic information systems (GIS) that do not provide estimates of wetland storage volumes or interception areas. Given these constraints, many modeling efforts have relied on estimating wetland volumes and interception areas by applying models that capture definable relationships between volume and wetland surface area. These models are then applied to available wetland area data (e.g., National Wetlands Inventory (NWI)) to estimate storage volumes. The overall goal of this study was to develop and apply predictive models to estimate the maximum water storage capacity and interception area of wetlands in the upper Mustinka subbasin, Grant County, Minn. Models we developed provided reasonably good estimates of wetland volumes and interception areas; however, we did identify several sources of error that need to be considered when applying the models. These sources of error include variation among methods used to define wetland boundaries (e.g., interpretation of aerial photography, ground survey) and models that do not account for morphological differences among physiographic regions in the Prairie Pothole Region. Using our models, we estimated that existing and restorable wetlands located in the upper Mustinka subbasin could intercept precipitation from up to 42 percent of the subbasin's $(52,758 \mathrm{ha})$ land area and have the potential to store 4,706 ha-m of water. Application of these models to the upper Mustinka subbasin demonstrated the spatial impact and maximum potential of wetlands to intercept precipitation and store water. 


\section{Methods}

\section{Study Area}

We surveyed restorable wetlands located within the upper Mustinka subbasin in the southern portion of Grant County, Minn. (fig. 2). Grant County is located in the eastern portion of the Glaciated Plains physiographic region in the southeast reach of the Red River of the North drainage basin (fig. 2). The upper Mustinka subbasin encompasses 52,758 ha and includes numerous watersheds that contribute water to the Mustinka River that eventually flows into the Red River of the North.

To identify restorable wetlands we used GIS data provided by the RWWG (2002). The RWWG was formed in 2002 and began mapping restorable wetlands in the Prairie Pothole Region of Minnesota and Iowa. The restorable wetlands GIS data consists of restorable (e.g., drained, farmed) wetlands identified through photo-interpretation and includes welldrained or altered wetlands that are not well accounted for by the NWI (fig. 3). To select study sites, we first identified watersheds that had relatively high densities of restorable wetlands and size distributions similar to that of the entire county. This method resulted in the selection of two watersheds that best met these criteria. We then identified sections of land within the watersheds with high densities of restorable wetlands. Following contact with landowners, we acquired permission to sample 95 potentially restorable wetlands on portions of 11 sections $(1.6 \times 1.6 \mathrm{~km})$ of land (fig. 2$)$.

\section{Topographic Surveys}

We conducted detailed topographic surveys of field sites to characterize the morphology of 95 restorable wetlands. We used a Trimble® 5700 GPS total station (Trimble, Sunnyvale, $\mathrm{CA}$ ) to conduct surveys that included the location and relative elevation of the entire wetland basin and catchment, as well as tile and/or surface drains. We then used the software program ForeSight $^{\mathrm{TM}}$ (Tripod Data Systems, Inc., 1997) to compute the surface area (ha) and volume (ha-m) of the wetland basin and the surface area (ha) of the catchment. The wetland basin area is delineated by the maximum elevation/spill point of the wetland, that is, the elevation at which surface water would flow out of the wetland basin and catchment and into an adjacent catchment, ditch, etc. (fig. 4). Wetland volume was determined by specifying the maximum elevation of the wetland in ForeSight and calculating the fill volume for the wetland polygon.

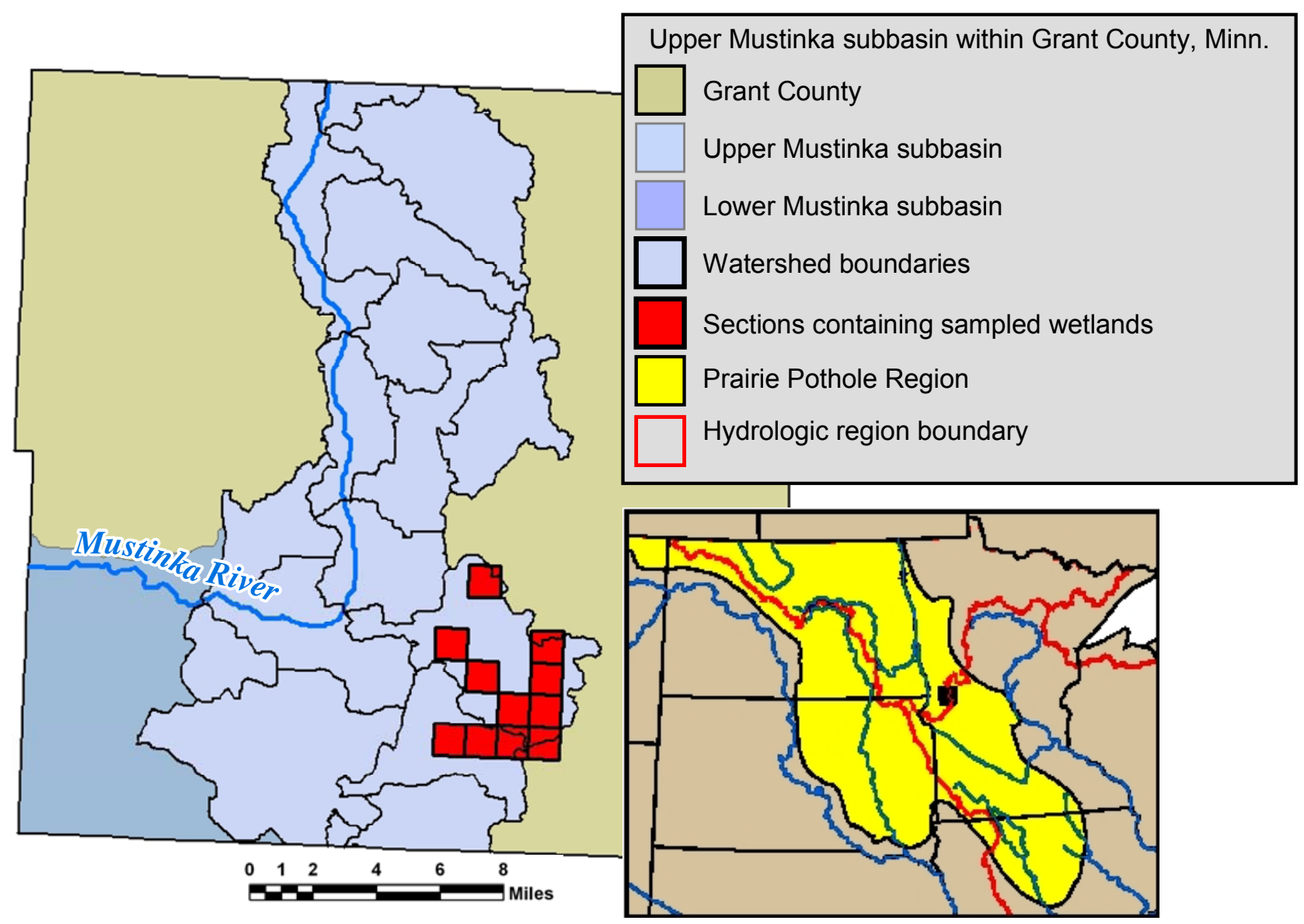

Figure 2. Location of sections $(1.6 \times 1.6 \mathrm{~km})$ where wetlands were surveyed in the upper Mustinka subbasin within Grant County, Minn. 
If the wetland was drained, volumes were calculated as if the hydrology was restored (e.g., fill-in ditch, break tile, etc.). The catchment area is defined as the area that contributes surface runoff to a wetland basin and was defined by constructing and interpreting contour maps and digital elevation models by using the survey data.

Upland areas sloping toward a wetland basin were considered part of the catchment, while areas sloping away from the wetland basin were considered outside of the catchment (fig. 4). The interception area is defined as the surface area of the catchment plus the surface area of the wetland basin (fig. 4). The interception area represents an area where precipitation is not routed "downstream" in a watershed through ditches or surface flow unless the wetland overflows. Figure 4 depicts the catchment, wetland, and interception areas as defined in this report. Figure 5 illustrates a typical spatial distribution of wetlands and catchments throughout a landscape; note that by definition catchment areas do not overlap and that there are areas in a landscape that do not contribute direct runoff to wetland basins. Also, note how much of the actual interception area (wetland plus catchment) would be overlooked if only the wetland basin were considered.

In the following sections of the report we refer to models developed with data from Gleason and Tangen (2006). These models were developed with survey data collected and analyzed by using the same methods as outlined above. The data used to develop these models were consolidated from multiple studies conducted across the entire Prairie Pothole Region (all physiographic regions) by scientists of the U.S. Geological Survey's Northern Prairie Wildlife Research Center in Jamestown, N. Dak. Information pertaining to this data may be obtained from the authors.

\section{Statistical Analyses/Model Development}

We performed linear regression analysis by using SAS software (SAS Institute, Inc., 2001) to determine the relationship of wetland surface area to volume and interception area. The data indicated that the response variables were distributed lognormal; therefore, we log transformed the responses to normalize and stabilize the variances. For all regression models, surface areas and volumes were transformed by using the natural logarithm (approximating model $\mathrm{Y}=\beta_{0} \mathrm{X}^{\mathrm{B} 1}$ ). We applied the wetland interception area and volume predictive models to wetland areas mapped by the NWI and the RWWG to estimate existing and potential interception area and maximum water storage capacity of palustrine wetlands in the upper Mustinka subbasin.

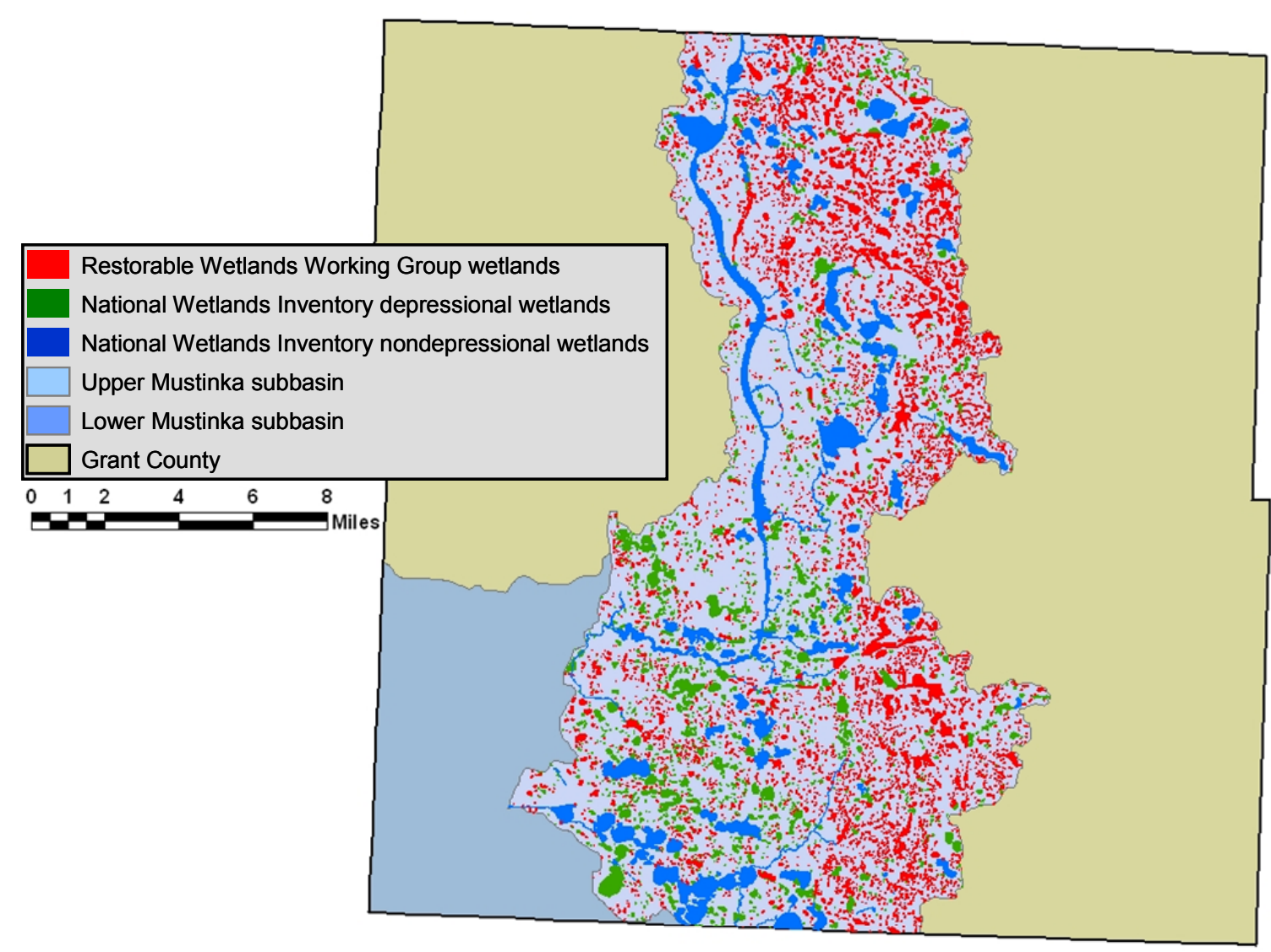

Figure 3. National Wetlands Inventory and Restorable Wetlands Working Group wetland data for the upper Mustinka subbasin within Grant County, Minn. 


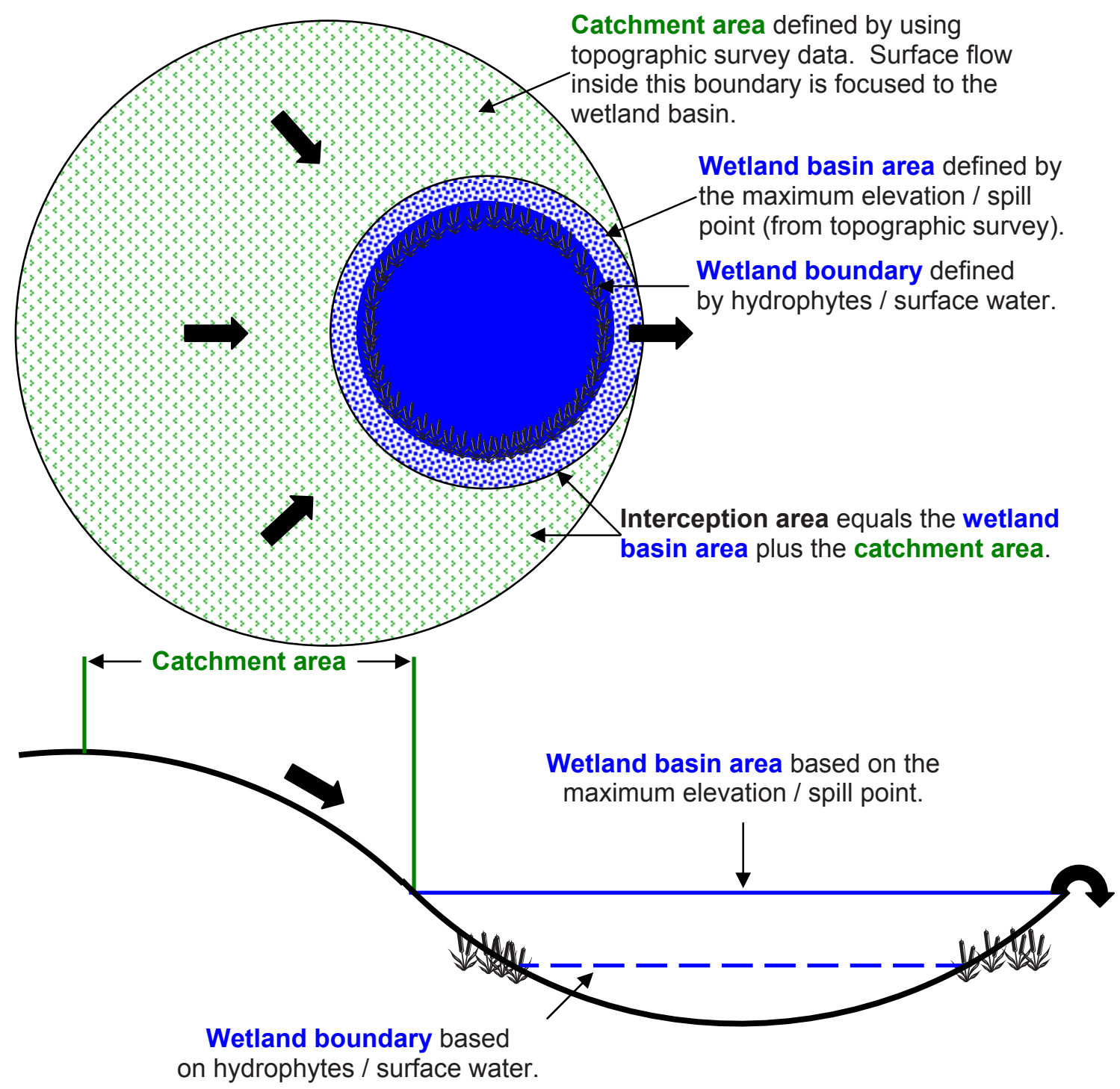

Figure 4. Plan and profile view of wetland and catchment areas as defined in this report. For the models presented in this report, the wetland basin area is defined by the maximum elevation or spill point of a wetland (from topographic survey data); this boundary is constant. Remote sensing methods (e.g., National Wetlands Inventory (NWI)) typically define wetland boundaries by using easily identifiable features such as surface water and/or hydrophytes; this boundary depends on current hydrologic conditions and is dynamic. The catchment area (from topographic survey data) is defined as the area that contributes runoff to a wetland. The interception area is the combination of the wetland basin area and the catchment area. Block arrows indicate direction of flow (i.e., runoff/surface flow). As demonstrated in the figure, boundaries based on surface water/vegetation may underestimate the actual topographic size of a wetland basin during periods when water levels are low. Applying area-based models to boundaries based on surface water/hydrophytes (e.g., NWI) to predict wetland volume could result in the underestimation of the actual water storage represented by the maximum elevation/spill point. 


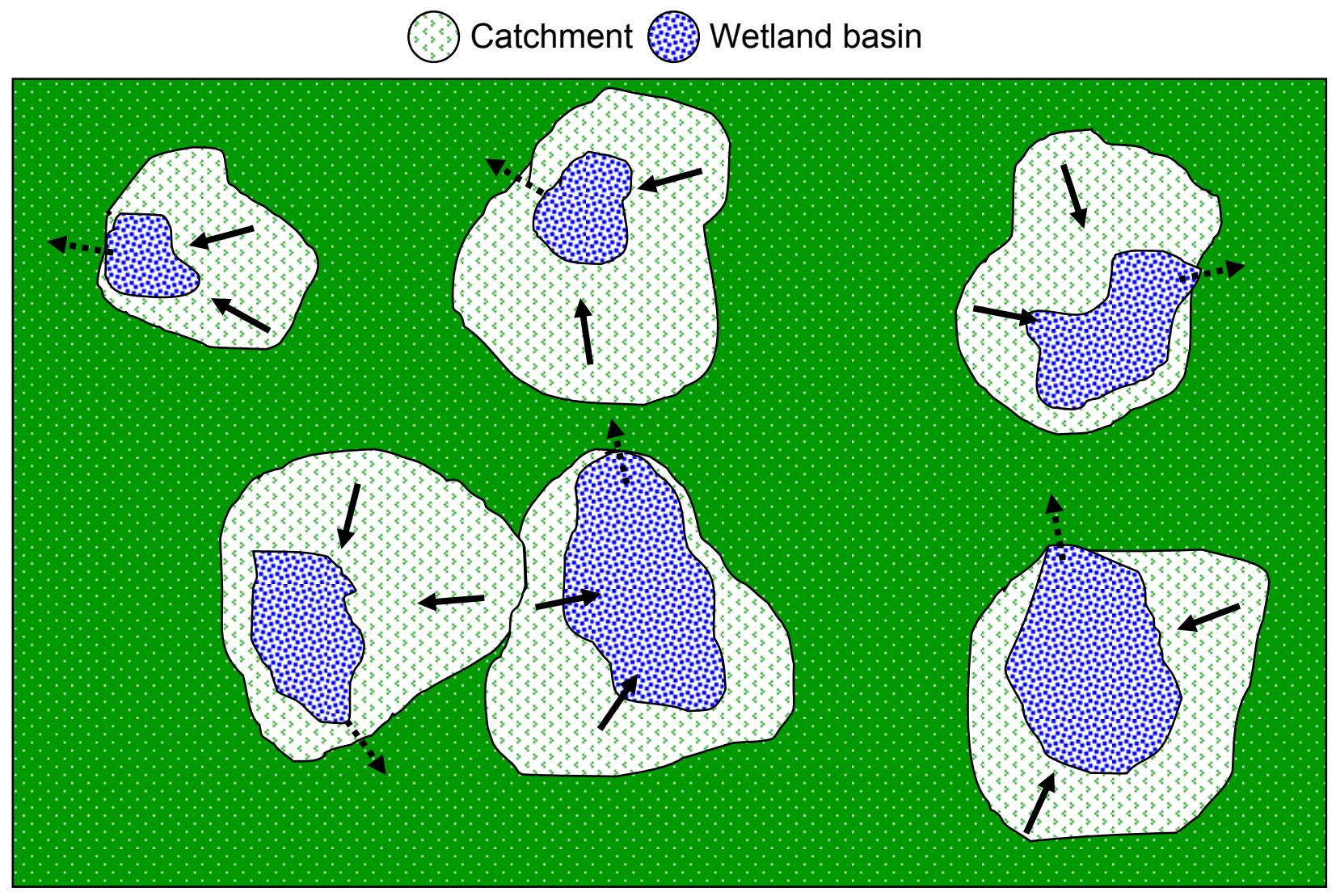

Figure 5. Representation of a typical spatial distribution of wetlands and catchments throughout a landscape. Catchment areas do not overlap, and there are areas in a landscape that do not contribute direct runoff to wetland basins (green area outside of wetland catchments). Block arrows show general directions of flow/runoff, and dotted arrows represent the overflow/spill point of the wetland/catchment (see fig. 4). Also, note how much of the actual interception area (wetland basin plus catchment) would be overlooked if the catchment areas were excluded.

\section{Results and Discussion}

\section{Evaluation of Surface Area to Volume Relationships}

Regression techniques indicated that wetland volume is strongly related $\left(r^{2}=0.96\right)$ to wetland basin area (table 1$)$. When our volume model is compared to a similar model developed with data from the Glaciated Plains physiographic region (Gleason and Tangen, 2006), we found good concordance among models (fig. 6); however, there are notable differences in models among regions (fig. 6) that demonstrate the importance of regionalized models to account for dissimilarity in relief and basin morphometry that varies throughout the physiographic regions of the Prairie Pothole Region.

Selecting a volume model developed for specific regions or landforms will reduce error (fig. 6); however, when estimating the maximum volume of a wetland, greater error may result if the wetland area input into the model is based on a depressional boundary that is topographically lower than the true maximum wetland elevation (i.e., overflow/spill elevation (see fig. 4)). For example, the NWI spatial wetland information is based on interpretation of aerial photography that identifies wetland features such as hydrophytes and surface water. Figure 4 demonstrates how wetlands delineated in this manner may underestimate the actual surface area and thus volumes predicted by using models based on wetland area. Key to reducing or adjusting for this type of error is to understand the relationship between the remotely sensed wetland areas (e.g., NWI) used as model input data to ground-based areas from which the model was developed. Using data from previous studies (Gleason and Tangen, 2006) on 123 wetlands with surface areas defined by using topographic survey data as well as spatial data from the NWI, we found surface areas from the NWI to be consistently smaller than ground-based area estimates derived from topographic surveys, regardless of physiographic region. Wetland surface areas from the NWI were found to account for only $58.6 \pm 5.8$ percent (mean \pm 95 percent confidence interval) of the surveyed wetland areas. 
Since this "bias" did not vary significantly with wetland size (fig. 7), it can be used to adjust wetland areas obtained from the NWI, prior to applying the model to predict volumes; however, this correction factor is based on the limited range of wetland sizes (0.18-11.29 ha) that were surveyed. Over this size range we found that this bias did not vary significantly with wetland surface area, but for larger, more stable wetlands this may not be the case. For example, it seems unlikely that the NWI would account for only 58 percent of a 100-ha wetland. Therefore, caution should be used when applying this correction factor to NWI wetland areas outside the size range that we sampled.

\section{Evaluation of Surface Area to Interception Area Relationships}

Interception area was found to be strongly related $\left(r^{2}=0.70\right)$ to wetland basin area (table 1$)$. We compared our interception area model to a similar model developed with data from the Glaciated Plains physiographic region (Gleason and Tangen, 2006). The models have the same general shape, but we found poor concordance among the Glaciated Plains models (fig. 8) compared to the consistency we observed for the volume models (fig. 6). Similar to the volume models, however, the results show the importance of limiting regional variation by selecting an interception area model according to the physiographic region of interest.

The model developed for the upper Mustinka subbasin predicted consistently higher interception areas than did the other model developed for the Glaciated Plains; the model also predicted greater interception areas than the models developed for the Missouri and Prairie Coteaus. The inconsistency among models from the same physiographic region is likely due, in part, to the fact that we surveyed restorable (i.e., drained, farmed (Restorable Wetlands Working Group, 2002)) wetlands in Grant County. Generally, the smaller wetlands are drained because of logistical and monetary constraints, and these wetlands were typically associated with relatively large, flat catchments that likely skewed the upper Mustinka subbasin model presented in figure 8. In general, the smaller the wetland, the larger the catchment area to wetland area ratio; this relationship is depicted in figure 9.

Table 1. Predictive models developed for restorable wetlands in the upper Mustinka subbasin of Grant County, Minn. (data from this study), and the three physiographic regions of the Prairie Pothole Region (Gleason and Tangen, 2006). The wetland volume and interception area models can be used in conjunction with spatial wetland data (e.g., National Wetlands Inventory) to predict wetland volumes and interception areas on large spatial scales.

[UMS, Upper Mustinka subbasin; PPR, Prairie Pothole Region]

\begin{tabular}{|c|c|c|c|c|c|c|c|c|}
\hline \multirow[b]{2}{*}{ Predicted variable } & \multirow{2}{*}{$\begin{array}{l}\text { Physiographic } \\
\text { region }\end{array}$} & \multirow[b]{2}{*}{ Source $^{1}$} & \multirow[b]{2}{*}{$\mathbf{n}$} & \multicolumn{2}{|c|}{ Size $^{2}$} & \multirow{2}{*}{ Model $^{3}$} & \multirow{2}{*}{ MSE $^{4}$} & \multirow{2}{*}{$\begin{array}{c}\text { Coefficient of } \\
\text { determination } \\
\left(r^{2}\right)\end{array}$} \\
\hline & & & & Mean & Range & & & \\
\hline Wetland volume & Glaciated Plains & UMS & 95 & 0.12 & $0.002-3.8$ & $\mathrm{~V}_{1}=0.201 \mathrm{~A}^{1.5029}$ & 0.50 & 0.96 \\
\hline Interception area & Glaciated Plains & UMS & 95 & 3.04 & $.06-14.24$ & $\mathrm{IA}_{1}=5.06 \mathrm{~A}^{0.5921}$ & .60 & .70 \\
\hline Wetland area & Glaciated Plains & UMS & 95 & .12 & $.002-3.8$ & $\mathrm{~A}_{1}=2.567 \mathrm{~V}^{0.6356}$ & .32 & .96 \\
\hline Wetland volume & Glaciated Plains & PPR & 288 & .92 & $.002-9.25$ & $\mathrm{~V}_{1}=0.25 \mathrm{~A}^{1.4742}$ & .69 & .91 \\
\hline Wetland volume & Missouri Coteau & PPR & 186 & 1.28 & $.01-11.29$ & $\mathrm{~V}_{1}=0.398 \mathrm{~A}^{1.542}$ & .73 & .91 \\
\hline Wetland volume & Prairie Coteau & PPR & 23 & 2.22 & $.24-7.08$ & $\mathrm{~V}_{1}=0.458 \mathrm{~A}^{1.5611}$ & .39 & .94 \\
\hline Interception area & Glaciated Plains & PPR & 288 & 3.11 & $.06-17.60$ & $\mathrm{IA}_{1}=3.43 \mathrm{~A}^{0.5765}$ & .55 & .70 \\
\hline Interception area & Missouri Coteau & PPR & 186 & 3.98 & $.14-28.91$ & $\mathrm{IA}_{1}=3.6 \mathrm{~A}^{0.6148}$ & .49 & .78 \\
\hline Interception area & Prairie Coteau & PPR & 23 & 6.08 & $1.07-16.11$ & $\mathrm{IA}_{1}=3.39 \mathrm{~A}^{0.7694}$ & .34 & .84 \\
\hline Wetland area ${ }^{5}$ & Glaciated Plains & PPR & 288 & .92 & $.002-9.25$ & $\mathrm{~A}_{1}=2.15 \mathrm{~V}^{0.6155}$ & .45 & .91 \\
\hline Wetland area ${ }^{5}$ & Missouri Coteau & PPR & 186 & 1.28 & $.01-11.29$ & $\mathrm{~A}_{1}=1.62 \mathrm{~V}^{0.59}$ & .45 & .91 \\
\hline Wetland area ${ }^{5}$ & Prairie Coteau & PPR & 23 & 2.22 & $.24-7.08$ & $\mathrm{~A}_{1}=1.64 \mathrm{~V}^{0.6043}$ & .25 & .94 \\
\hline
\end{tabular}

${ }^{1}$ If source is UMS, then the model was developed with data collected for this study from the upper Mustinka subbasin. If source is PPR, then model was developed with data collected from multiple studies across the entire Prairie Pothole Region (Gleason and Tangen, 2006).

${ }^{2}$ For wetland volume/area models, size refers to wetland area (ha); for interception area models, size refers to interception area (ha).

${ }^{3} \mathrm{~V}_{1}=$ predicted wetland volume, $\mathrm{V}=$ measured maximum wetland volume $($ ha- $\mathrm{m}) ; \mathrm{I}_{1}=$ predicted interception area, $\mathrm{A}_{1}=$ predicted wetland area, $\mathrm{A}=$ measured maximum wetland area (ha).

${ }^{4}$ Mean square error (MSE) from log transformed (natural logarithm) data.

${ }^{5}$ The wetland area model is used to recalculate wetland surface area in the wetland water storage simulation model presented in chapter B. 


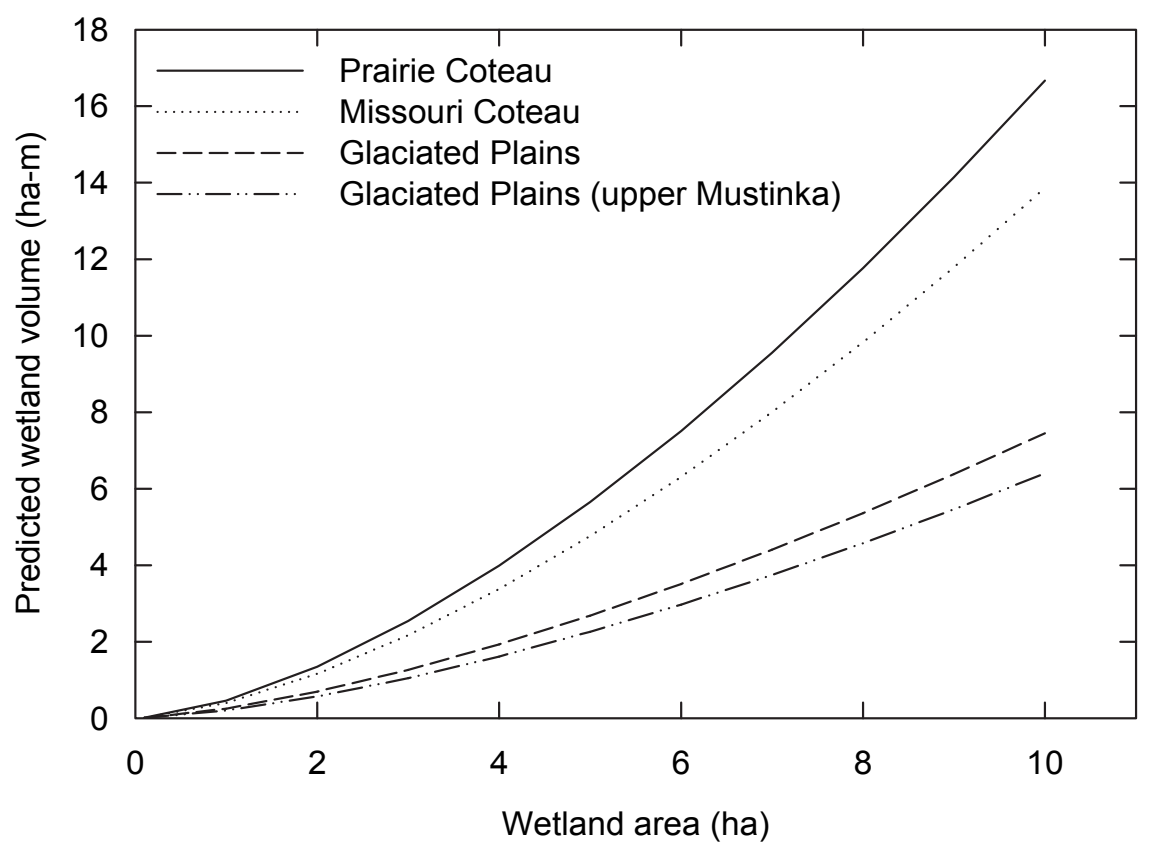

Figure 6. Comparison of surface area-volume relationships among the model developed for the upper Mustinka subbasin and models for the three physiographic regions of the Prairie Pothole Region (Gleason and Tangen, 2006). Predicted volumes for the Prairie Coteau and Missouri Coteau are generally greater than those for the Glaciated Plains, and the regional differences among predicted volumes increase with wetland surface area. The model developed for this study (Glaciated Plains; upper Mustinka) shows good concordance with the model developed with data from across the Glaciated Plains.

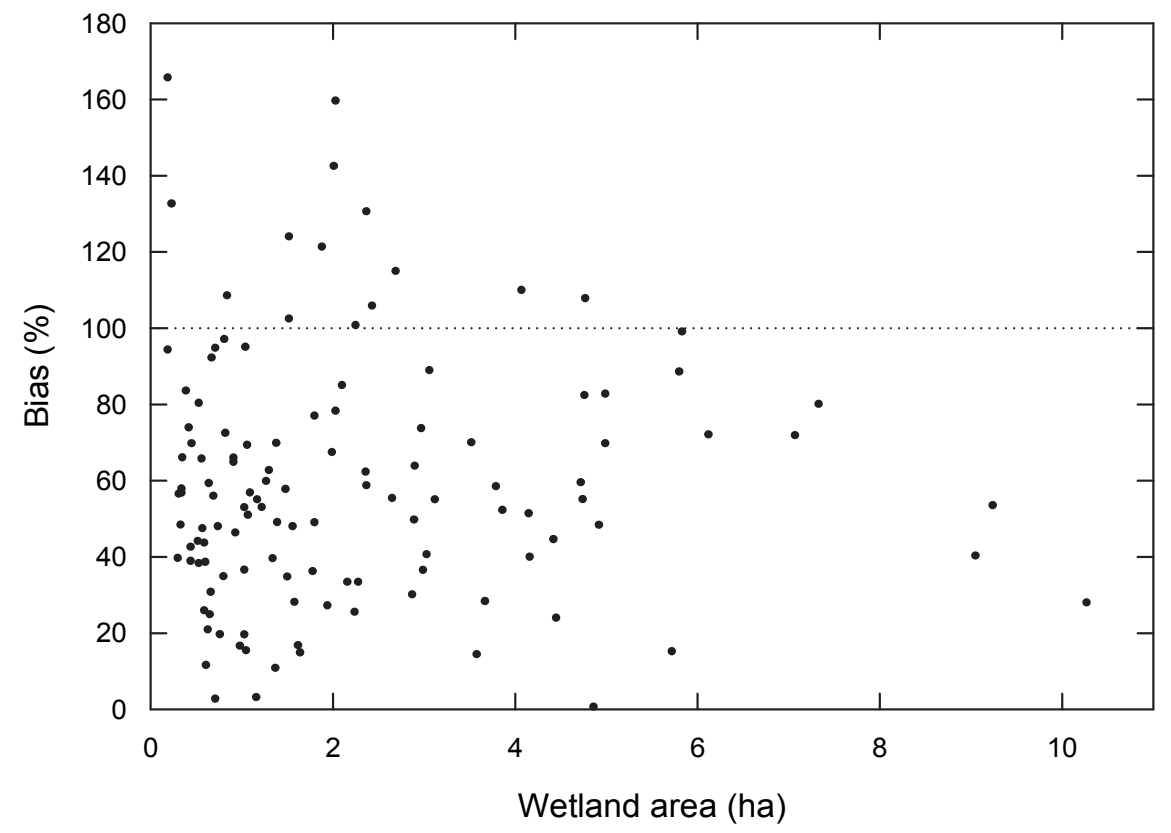

Figure 7. Relationship between 123 wetland surface areas obtained from the National Wetlands Inventory (NWI) and areas for the same sites obtained from ground-based topographic surveys. A bias ((wetland area from NWI/wetland area from survey) $\times 100$ ) greater than 100 percent represents an overprediction of wetland area by the NWI, while a bias of less than 100 percent represents an underprediction. Overall, the wetland areas obtained from the NWI are smaller than areas determined by using the maximum wetland elevation, and there is no significant correlation between wetland size and NWI bias. 


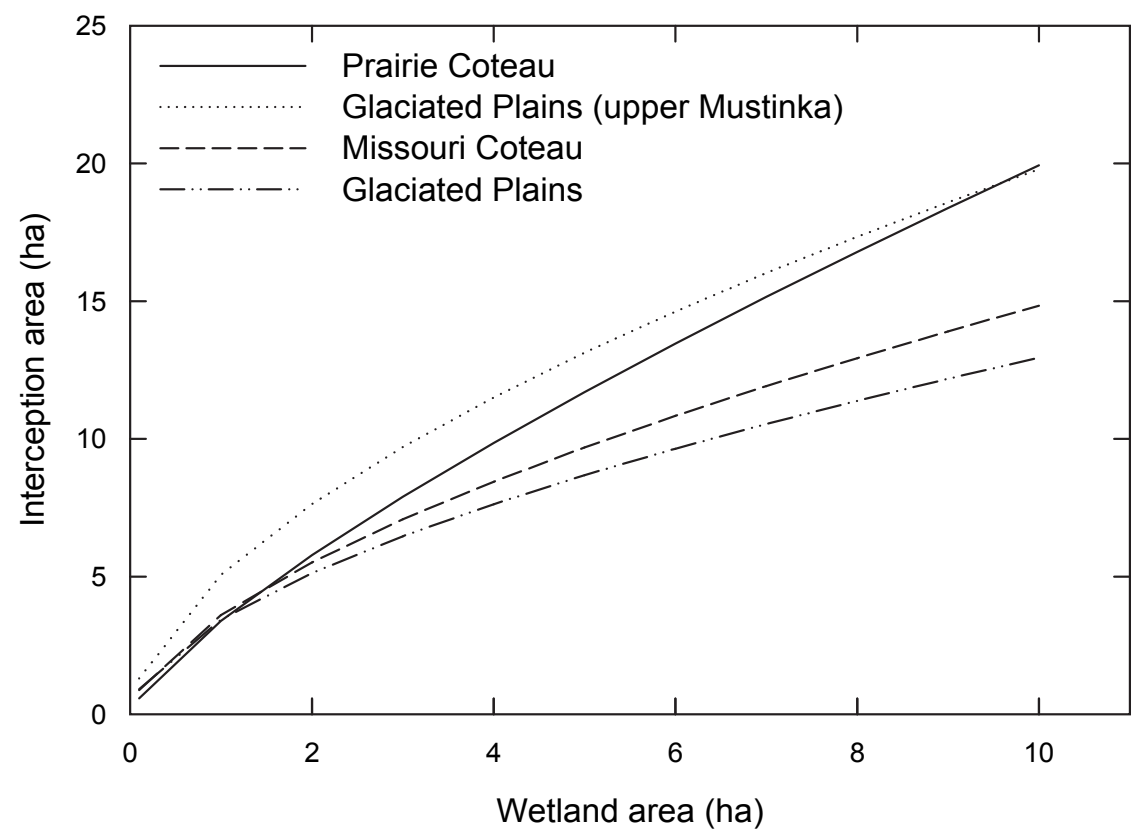

Figure 8. Comparison of surface area-interception area relationships among the model developed for the upper Mustinka subbasin and models for the three physiographic regions of the Prairie Pothole Region (Gleason and Tangen, 2006). There is poor concordance among the two models developed for the Glaciated Plains. The model developed for the upper Mustinka subbasin more closely resembles the model developed for the Prairie Coteau. This discrepancy is likely due to the relatively small size of the wetlands sampled in Grant County compared to their respective catchments.

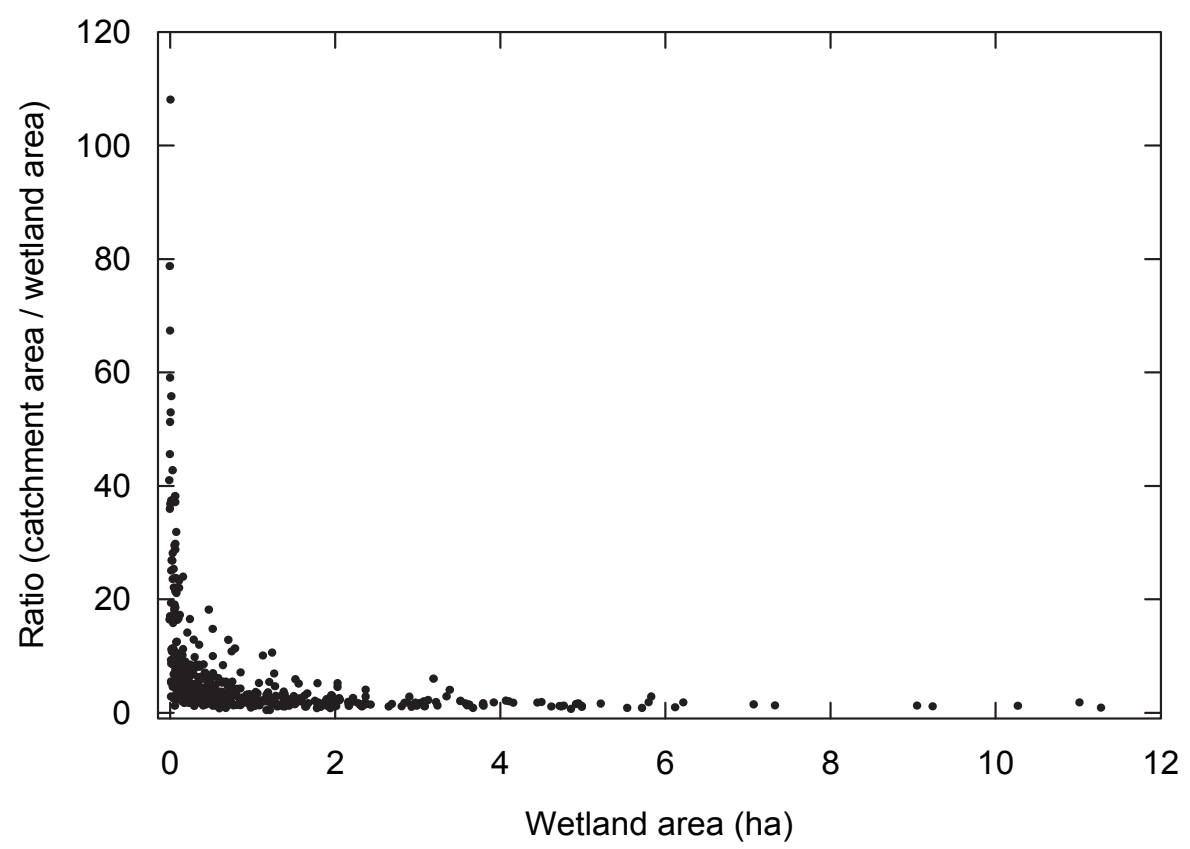

Figure 9. Catchment area-wetland area ratios (catchment area/wetland area) relative to wetland size (data from current study and from Gleason and Tangen, $2006(n=503)$ ). There was no strong relationship between ratios and wetland size; however, ratios were noticeably higher for a portion of the smaller wetlands. 


\section{Estimating Depressional Storage and Interception Areas}

We applied models (table 1) to estimate the maximum potential storage volume and interception area of depressional (i.e., palustrine) wetlands mapped by the NWI and restorable wetlands mapped by the RWWG in the upper Mustinka subbasin (fig. 3). Based on the NWI and the RWWG databases, there were 2,060 existing depressional wetlands totaling 2,397 ha and 6,161 potentially restorable wetlands totaling 2,819 ha in the upper Mustinka subbasin (fig. 3). Prior to estimating maximum storage volumes and interception areas of existing NWI wetlands, we adjusted NWI areas by following procedures described earlier (see Evaluation of Surface Area to Volume Relationships). Also, we only included volume and interception area estimates for 54 percent (randomly selected) of the restorable wetlands that were less than 0.7 ha in area. This adjustment was based on a ground-based error estimate that indicated that 54 percent of the restorable wetlands less than 0.7 ha in area may be depressions capable of storing water. Our ground-based assessment indicated that, in addition to being small (i.e., $<0.7$ ha), most sites identified as being nondepressions were likely inundated by ephemeral runoff from precipitation or snow melt; were typically influenced by roadbeds, ditches, and elevated fence lines; and were often associated with sloping drainage areas.

We predicted that existing wetlands could store 3,397 ha-m of water and that restorable wetlands have potential to store an additional 1,309 ha-m of water (table 2). Hence, restoration of wetlands has potential to increase existing storage in the subbasin by approximately 38 percent. Examination of the spatial variation in existing and restorable wetland water storage in the subbasin depicts which watersheds have the greatest potential to store water (fig. 10). Interception areas of existing and restorable wetlands accounted for 20.6 percent $(10,859$ ha $)$ and 21.7 percent $(11,444$ ha) of the total area of the upper Mustinka subbasin, respectively (table 2; fig. 11).

\section{Conclusion}

The overall goal of this study was to develop and apply predictive models to estimate maximum wetland water storage capacity and interception areas. To develop these models we used relatively simple survey methods to measure wetland morphologic characteristics and calculate wetland surface areas, interception areas, and volumes. Models developed from these data provided reasonably good estimates of wetland volumes and interception areas. We also identified how to correct for errors associated with remotely sensed data (i.e., NWI correction factor; see above Evaluation of Surface Area to Volume Relationships) and highlighted the need to apply region-specific models. Application of these models to the upper Mustinka subbasin demonstrated the spatial impact and maximum potential of wetlands to intercept precipitation and store water. Hence, application of our models to areal GIS data provided a spatially distributed framework from which to evaluate the potential of wetlands to intercept and store precipitation. With moderate calibration and testing, our models should have wide applicability in the development of spatially distributed hydrologic models used to predict the effects of wetland water storage on peak river flows.

Table 2. Maximum storage volumes and interception areas of existing and potentially restorable wetlands in the upper Mustinka subbasin of Grant County, Minn.

[NWI, National Wetlands Inventory]

\begin{tabular}{lrrrr}
\hline \multicolumn{1}{c}{ Wetland type } & Area (ha) & Volume (ha-m) & \multicolumn{2}{c}{ Interception } \\
\cline { 4 - 5 } & & & Area (ha) & \% area of subbasin' \\
\hline Existing NWI wetlands & 2,397 & 3,397 & 10,859 & 20.6 \\
Restorable wetlands $<0.7$ ha & 479 & 51 & 4,568 & 8.7 \\
Restorable wetlands $>0.7$ ha & $\underline{2,340}$ & $\underline{\mathbf{1 , 2 5 8}}$ & $\underline{6,876}$ & $\underline{\mathbf{1 3 . 0}}$ \\
Total & $\mathbf{5 , 2 1 6}$ & $\mathbf{4 , 7 0 6}$ & $\mathbf{2 2 , 3 0 3}$ & $\mathbf{4 2 . 3}$ \\
\hline
\end{tabular}

${ }^{1}$ Percent area of the upper Mustinka subbasin (52,758 ha). 

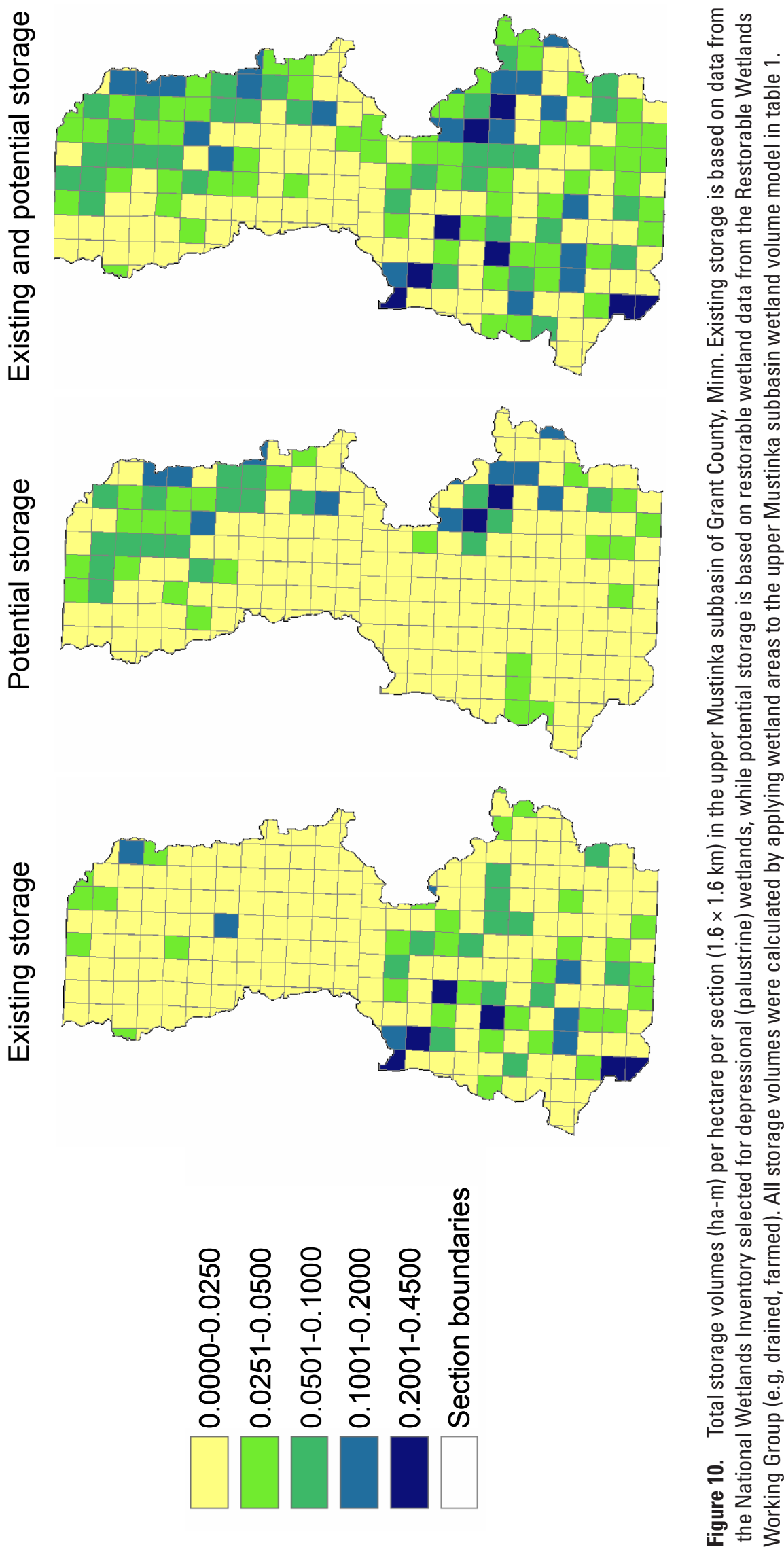


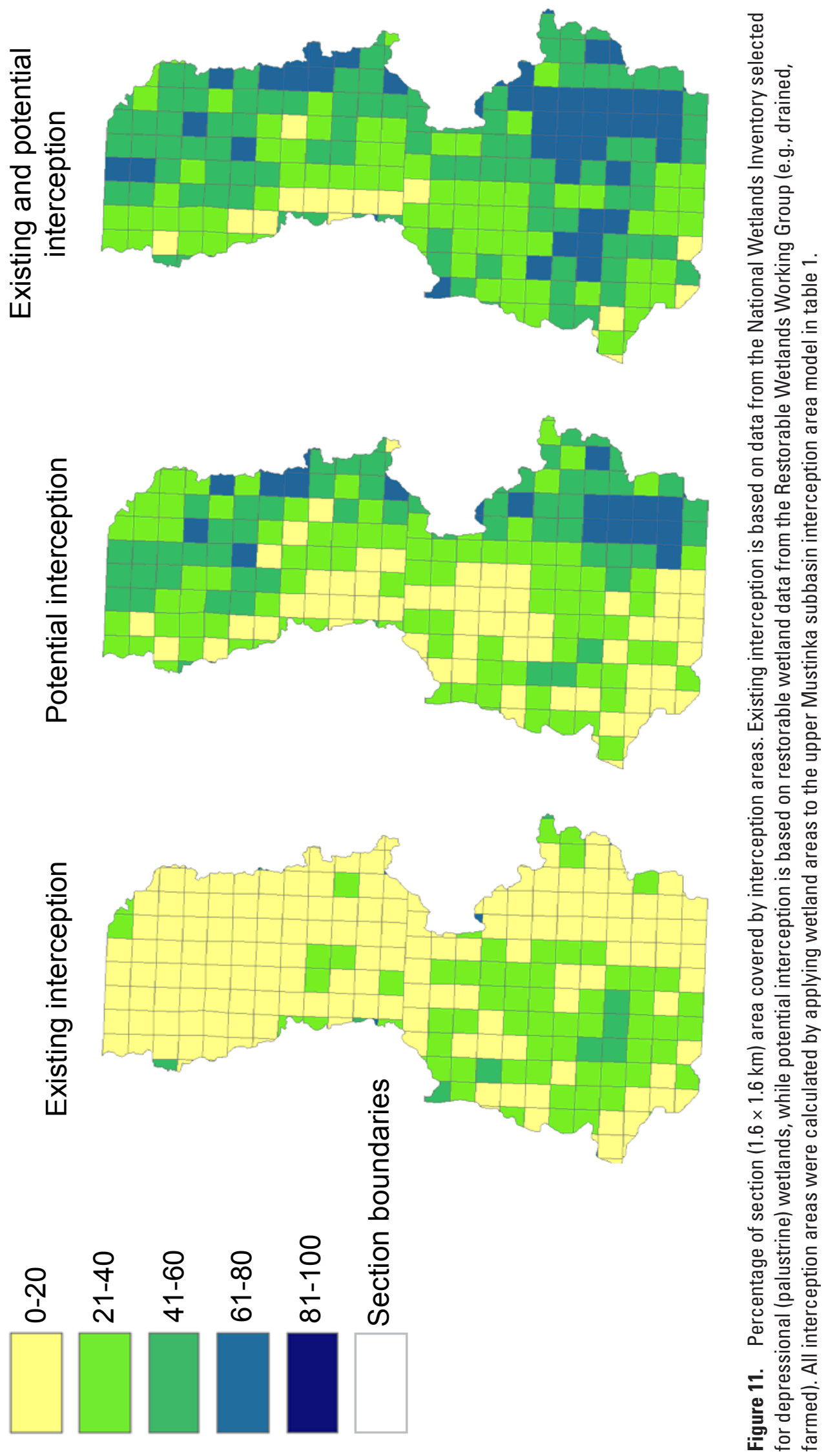




\section{Chapter B: Wetland Water Storage Simulation Model}

\section{Overview}

Attempts to model the impacts of wetland water storage on peak river flows have been constrained by lack of methods to simulate how precipitation is intercepted, processed, and stored by wetlands. Most often, modeling efforts have treated water stored by wetlands within a watershed as a simple lump storage component that is filled before overflow is routed to a pour point or gaging station. This approach does not account for dynamic hydrologic processes that influence water stored in prairie wetlands. Further, most models have not considered the influence of human-induced hydrologic changes, such as land use, that greatly influence quantity of surface water inputs and, ultimately, the rate that wetland basins fill and spill.

The goal of our study was to develop a simple model to simulate wetland water storage to provide a basis from which to understand and predict the effects of natural or humaninduced hydrologic alterations. Requisites for the model included that it (1) runs by using the standard statistical software program SAS (SAS Institute, Inc., 2001), (2) uses simple and widely available input data to simulate wetland hydrology and predict wetland volume for a specific precipitation event or a series of events, and (3) must account for effects of land use and soil type on surface water inputs. The model we developed to predict water stored by wetlands includes a function of water inputs from direct precipitation and surface water inflow and water losses from evapotranspiration and surface water outflow; the model met all predefined requisites. Further, simulation tests demonstrated that the model provided reasonably good estimates of actual changes in wetland water storage, and on average, volume estimates were within 0.08 ha-m of known values.

\section{Methods}

\section{Model Development/Assumptions}

Our goal was to develop a model that uses simple input variables (e.g., daily precipitation, daily evapotranspiration rate estimate, surface runoff estimates) to simulate and predict wetland water storage for a specific precipitation event (e.g., a 3-day rain event) or a series of events (e.g., for 1 or more years). We also wanted the model to account for differences in land use (e.g., row crop, small grain, meadow, pasture, etc.) and soil types that influence surface water inputs. To develop the model we first considered major hydrologic components that influence water received or lost from wetlands; these major hydrologic components are expressed in the following water storage equation:

$$
\mathrm{WS}=\mathrm{SS}+(\mathrm{P}+\mathrm{GWI}+\mathrm{SWI})-(\mathrm{ET}+\mathrm{GWO}+\mathrm{SWO})
$$

where

$$
\begin{aligned}
\text { WS } & =\text { water stored, } \\
\mathrm{SS} & =\text { starting storage, } \\
\mathrm{P} & =\text { precipitation, } \\
\mathrm{GWI} & =\text { ground water inflow, } \\
\mathrm{SWI} & =\text { surface water inflow, } \\
\mathrm{ET} & =\text { evapotranspiration, } \\
\mathrm{GWO} & =\text { ground water outflow, and } \\
\mathrm{SWO} & =\text { surface water outflow. }
\end{aligned}
$$

Ideally all sources of water inputs (i.e., P, GWI, SWI) and outputs (i.e., ET, GWO, SWO) would be included in a model to predict wetland water storage; however, early in the development of the model, we decided not to include a ground water flow function (i.e., GWO and GWI) because ground water flow in prairie wetlands is highly complicated (Winter, 1989). For example, wetlands may serve as a recharge area for ground water (i.e., GWO), a discharge area for ground water (i.e., GWI), or both a recharge and discharge area for ground water (e.g., GWO and GWI). Spatial databases available on wetlands (e.g., National Wetlands Inventory (NWI)), to which our model would be applied, do not provide information necessary to classify the relationship of a wetland to ground water flow systems. Nevertheless, the lack of a ground water function in the model is not expected to greatly compromise model performance. For example, because of the slow rate of ground water movement in prairie wetlands $\left(0.025\right.$ to $2.5 \mathrm{~m} \mathrm{yr}^{-1}$ (Winter and Rosenberry, 1995)), dynamic changes in wetland water storage are not strongly correlated to GWO or GWI. Rather, direct P and SWI are known to be the primary sources of water to prairie wetlands, and ET accounts for the largest loss of water from prairie wetlands (Winter, 2003). Hence, in an overall water budget, GWI and GWO contribute the least. When excluding the ground water function, the model we developed to predict wetland water storage for a specific precipitation event, $\mathrm{t}$, is expressed in the following equation:

$$
\mathrm{WS}_{\mathrm{t}}=\left(\mathrm{WS}_{\mathrm{t}-1}+\mathrm{P}_{\mathrm{t}}+\mathrm{SWI}\right)-\left(\mathrm{ET}_{\mathrm{t}}+\mathrm{SWO}_{\mathrm{t}}\right)
$$

where

$$
\begin{aligned}
\mathrm{WS}_{\mathrm{t}} & =\text { water stored for event } \mathrm{t} \\
\mathrm{WS}_{\mathrm{t}-1} & =\text { water stored prior to event } \mathrm{t} \\
\mathrm{P}_{\mathrm{t}} & =\text { direct precipitation inputs during event } \mathrm{t} \\
\mathrm{SWI}_{\mathrm{t}} & =\text { surface runoff inputs during event } \mathrm{t}, \\
\mathrm{ET}_{\mathrm{t}} & =\text { evapotranspiration during event } \mathrm{t}, \text { and } \\
\mathrm{SWO}_{\mathrm{t}} & =\text { surface water outflows during event } \mathrm{t} .
\end{aligned}
$$

An important consideration when developing the above model was that it could be run by using simple yet easily obtained precipitation, soil, and wetland data. Below, we provide a general overview of data inputs necessary to run the model and a general overview of methods used to calculate model components in the above equation. More detailed information on model inputs and calculations are presented in appendixes 1-7, including SAS code used to create input databases and run the model. 


\section{Data Inputs and Sources}

Wetland area (ha): Wetland area can be determined through field surveys or from existing databases such as the NWI.

Maximum Wetland Storage Volume (ha-m): Maximum potential water storage can determined through field surveys or estimated by using wetland area to volume relationships described in chapter A.

Catchment Area (ha): Wetland catchment area can be determined through field surveys or estimated by using wetland area to catchment area relationships described in chapter A.

Wetland Area and Catchment Area Land Use: Land use (e.g., cropland, grassland) can be acquired through field surveys or from existing databases such as the U.S. Geological Survey's (USGS) National Land Cover Dataset (http:// landcover.usgs.gov/).

Wetland Area and Catchment Area Hydrologic Soil Group: Hydrologic soil group of wetland and catchment areas can be determined by using Standard Soil Surveys or other databases such as the U.S. Department of Agriculture's (USDA) Soil Survey Geographic (SSURGO) database (www.ncgc.nrcs.usda.gov/products/datasets/ssurgo/).

Wetland Area and Catchment Area Surface Runoff Curve Number: Specific runoff curve numbers can be determined by using the USDA National Engineering Handbook (ftp://ftp.wcc.nrcs.usda.gov/downloads/hydrology hydraulics/neh630/). Surface runoff curves are unique to specific land uses and hydrologic soil groups.

Daily Precipitation: Precipitation data can be gathered through field measurement or obtained from a variety of weather monitoring networks.

\section{General Model Calculations}

For a given precipitation event, $t$, the model incorporates estimates of water input from three sources: (1) surface water runoff contributed from the catchment, (2) surface water runoff contributed from the nonponded portion of the wetland, and (3) direct precipitation contributed to the ponded portion of the wetland basin. Catchment zones used in the model (e.g., catchment, ponded and nonponded portion of wetland basin) are illustrated and described in figure 12. Surface water inputs $\left(\mathrm{SWI}_{\mathrm{t}}\right)$ derived from the catchment and nonponded portion of the wetland are estimated by using surface runoff curve numbers that are unique to specific hydrologic soil groups and land use types (e.g., grass and cultivated). Runoff curve numbers account for cover and soil factors that influence the generation and contribution of surface runoff to the wetland. Details on selection of runoff curve numbers are described in appendix 1 . In contrast, the ponded portion of the basin was estimated as receiving 100 percent of the precipitation. For simplicity, to account for evapotranspiration (ET) we used a constant average daily rate based on seasonal averages available in the literature; although it would increase labor and model complexity, a daily ET rate would likely improve model performance to some degree. Once maximum water storage volume of the basin is attained, any additional water input is treated as $\mathrm{SWO}_{\mathrm{t}}$. Following each simulation event, $\mathrm{t}$, the model recalculates the ponded and nonponded areas of the wetland basin (fig. 12) and uses these areas for the next simulation event.

\section{Calibration of Wetland Water Storage Model}

We calibrated the model by using precipitation, water level, and topographic data from 15 wetlands at the Cottonwood Lake study area located in Stutsman County, N. Dak. The Cottonwood Lake area is a long-term study site located near the eastern edge of the Missouri Coteau and includes a complex of wetlands that have been intensively monitored for over 30 years.

Daily precipitation data and water level data for the Cottonwood Lake study area was provided by the U.S. Geological Survey, Northern Prairie Wildlife Research Center, Jamestown, N. Dak. After reviewing this data, we decided to simulate changes in water storage in 15 wetlands for the period of April 14 to September 21, 1993. This period was selected for simulation because of the completeness of available precipitation and water level data and because 1993 had a high frequency of precipitation events. For this calibration, the precipitation data were grouped by event, defined as consecutive days with or without precipitation (table 3). Precipitation events grouped in this way better account for antecedent moisture conditions that influence generation of surface runoff.

All of the Cottonwood Lake area wetlands included in the simulation are surrounded by grass and have similar soil types (i.e., similar land use and hydrologic soil groups). We used procedures described in appendix 1 to determine runoff curve numbers for the catchment and the nonponded portion of each wetland basin. For example, the runoff curve number for all wetland catchments was 58 (e.g., land use $=$ meadow, hydrologic soil group = B, AMC = II, hydrologic condition = good), and the runoff curve number for the nonponded portion of the wetland was 78 (land use $=$ meadow, hydrologic soil group $=$ $\mathrm{D}, \mathrm{AMC}=\mathrm{II}$, hydrologic condition = good). For all wetlands, the ponded portion of the wetland received 100 percent of the precipitation. The daily evapotranspiration rate was set at $0.358 \mathrm{~cm} \mathrm{~d}^{-1}$ (Parkhurst and others, 1998).

\section{Results and Discussion}

Overall, the model performed well with simulated volumes resembling changes of actual volumes (figs. 13A, 13B, and $13 C$ ). Comparison of predicted volumes to actual volumes for 10 points (i.e., 10 "actual" volumes in figs. $13 A-C$ ) over the simulation period indicated a mean difference (absolute) of 0.08 ha-m $(\mathrm{SE}=0.01)$. Of the 15 Cottonwood Lake wetlands, 8 are classified as semipermanent, and 7 are classified as seasonal (classification follows Stewart and Kantrud, 1971). 

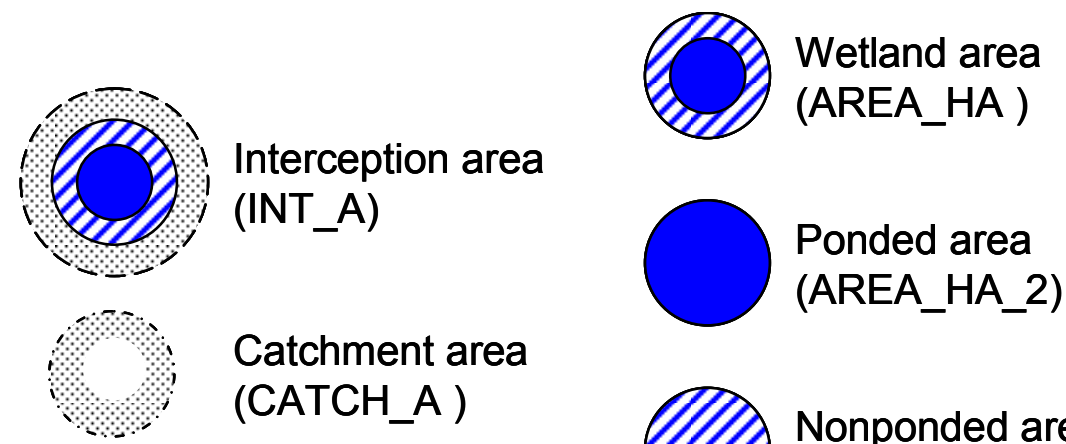

(AREA_HA_2)

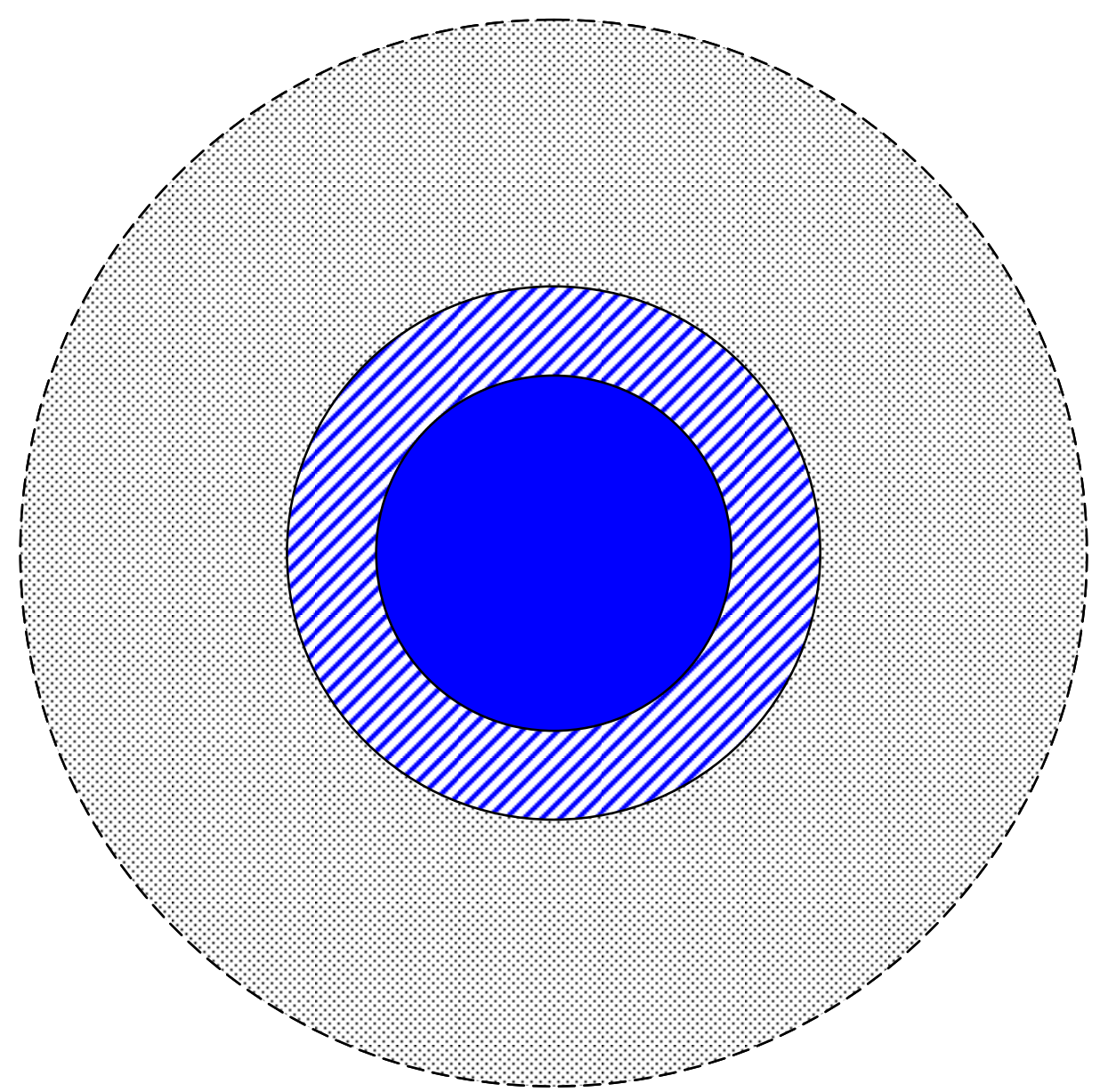

Figure 12. Catchment and wetland zones used in wetland water storage simulation model. The interception area (INT_A) refers to the highest elevation of the wetland basin (AREA_HA) and its entire contributing area or catchment (CATCH_A); see also figure 4. The area of the wetland basin is determined from topographic survey data and is constant regardless of the current state of the hydrophytic vegetation or water level. Therefore, the wetland basin comprises two areas, the ponded (AREA_HA_2) and nonponded (CATCH_A_2) portions. The ponded portion represents the area of standing water, and the nonponded portion represents the area of the wetland basin that does not contain standing water. If a wetland were filled to the maximum water holding capacity, then there would not be a nonponded portion. 
Table 3. Precipitation events used in the calibration of the simulation model for the time period of April 14 to September 21, 1993.

\begin{tabular}{|c|c|c|}
\hline Event number & Number of days in event & Precipitation $(\mathbf{c m})$ \\
\hline 1 & 9 & 0 \\
\hline 2 & 3 & .56 \\
\hline 3 & 1 & 0 \\
\hline 4 & 3 & .51 \\
\hline 5 & 6 & 0 \\
\hline 6 & 6 & 6.63 \\
\hline 7 & 10 & 0 \\
\hline 8 & 4 & 2.06 \\
\hline 9 & 1 & 0 \\
\hline 10 & 5 & 3.15 \\
\hline 11 & 5 & 0 \\
\hline 12 & 5 & 3.86 \\
\hline 13 & 2 & 0 \\
\hline 14 & 2 & .71 \\
\hline 15 & 1 & 0 \\
\hline 16 & 2 & 1.12 \\
\hline 17 & 5 & 0 \\
\hline 18 & 5 & 4.14 \\
\hline 19 & 1 & 0 \\
\hline 20 & 13 & 8.51 \\
\hline 21 & 1 & 0 \\
\hline 22 & 17 & 19.23 \\
\hline 23 & 4 & 0 \\
\hline 24 & 3 & .13 \\
\hline 25 & 2 & 0 \\
\hline 26 & 1 & .03 \\
\hline 27 & 2 & 0 \\
\hline 28 & 5 & 2.41 \\
\hline 29 & 1 & 0 \\
\hline 30 & 1 & .03 \\
\hline 31 & 5 & 0 \\
\hline 32 & 2 & .08 \\
\hline 33 & 1 & 0 \\
\hline 34 & 6 & 5.51 \\
\hline 35 & 3 & 0 \\
\hline 36 & 3 & .20 \\
\hline 37 & 13 & 0 \\
\hline 38 & 2 & .05 \\
\hline
\end{tabular}




\section{$\boldsymbol{A}$}

Predicted volume

Actual volume

Precipitation
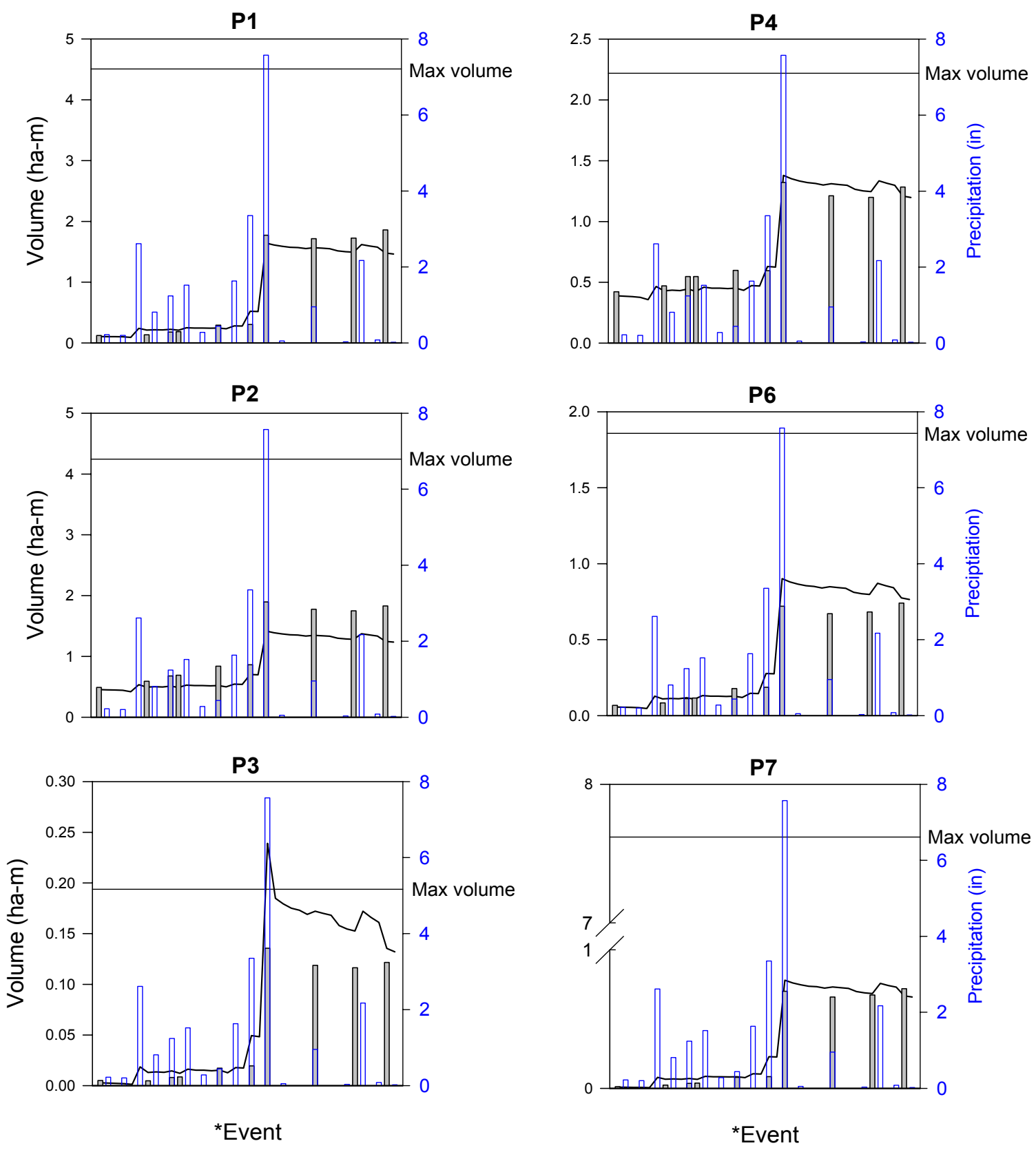

$*$ Event $=1-38($ see table 3$)$

Figure 13. Simulation model calibration for the Cottonwood Lake study area wetlands for the time period of April 14 to September 21, 1993. A, P1, P2, P3, P4, P6, and P7; B, P8, T2, T3, T4, T5, and T6; and C, T7, T8, and T9. 
B

Predicted volume

Actual volume

Precipitation
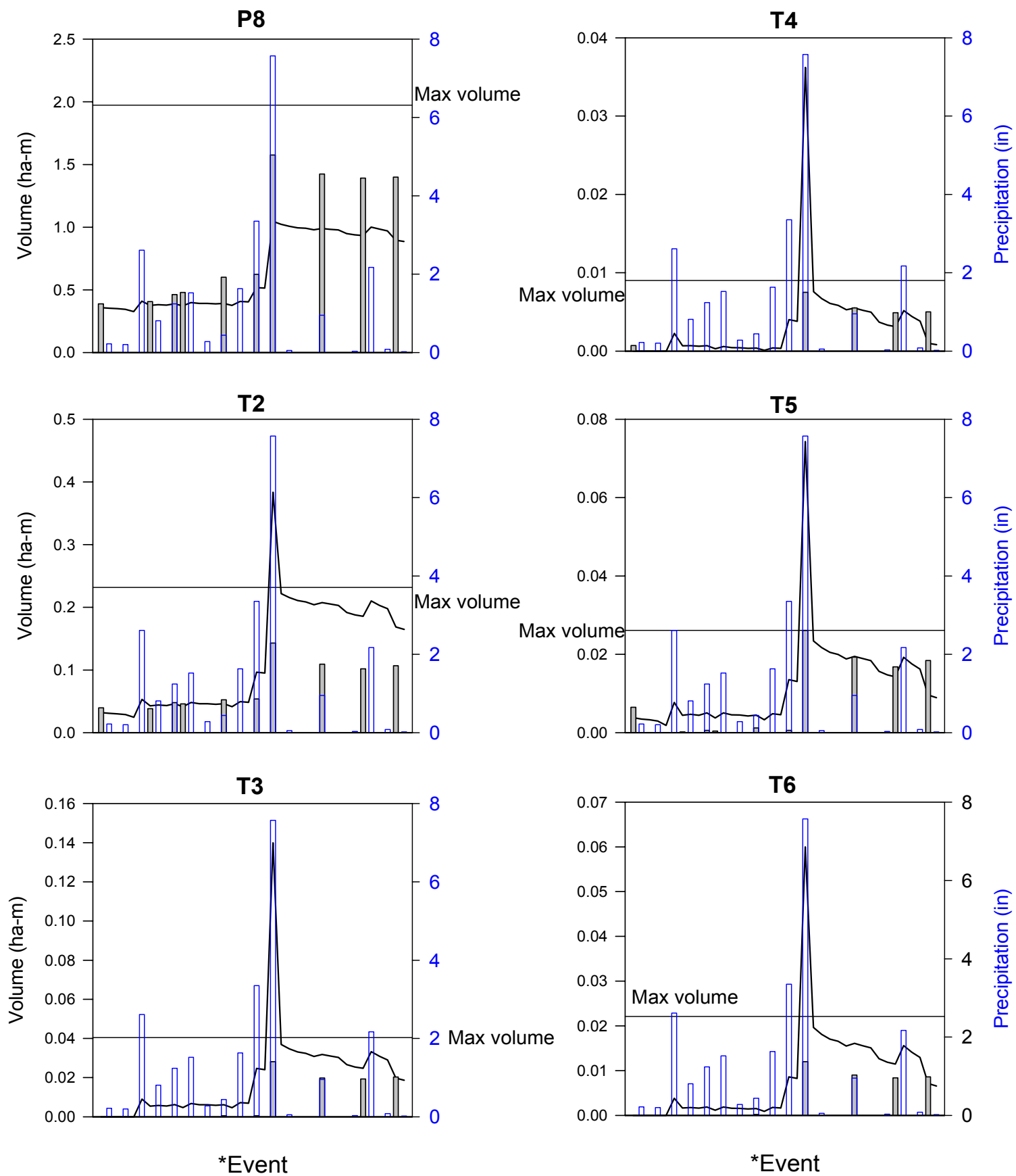

$*$ Event $=1-38($ see table 3$)$

Figure 13. Simulation model calibration for the Cottonwood Lake study area wetlands for the time period of April 14 to September 21, 1993. A, P1, P2, P3, P4, P6, and P7; B, P8, T2, T3, T4, T5, and T6; and C, T7, T8, and T9.-Continued 
C
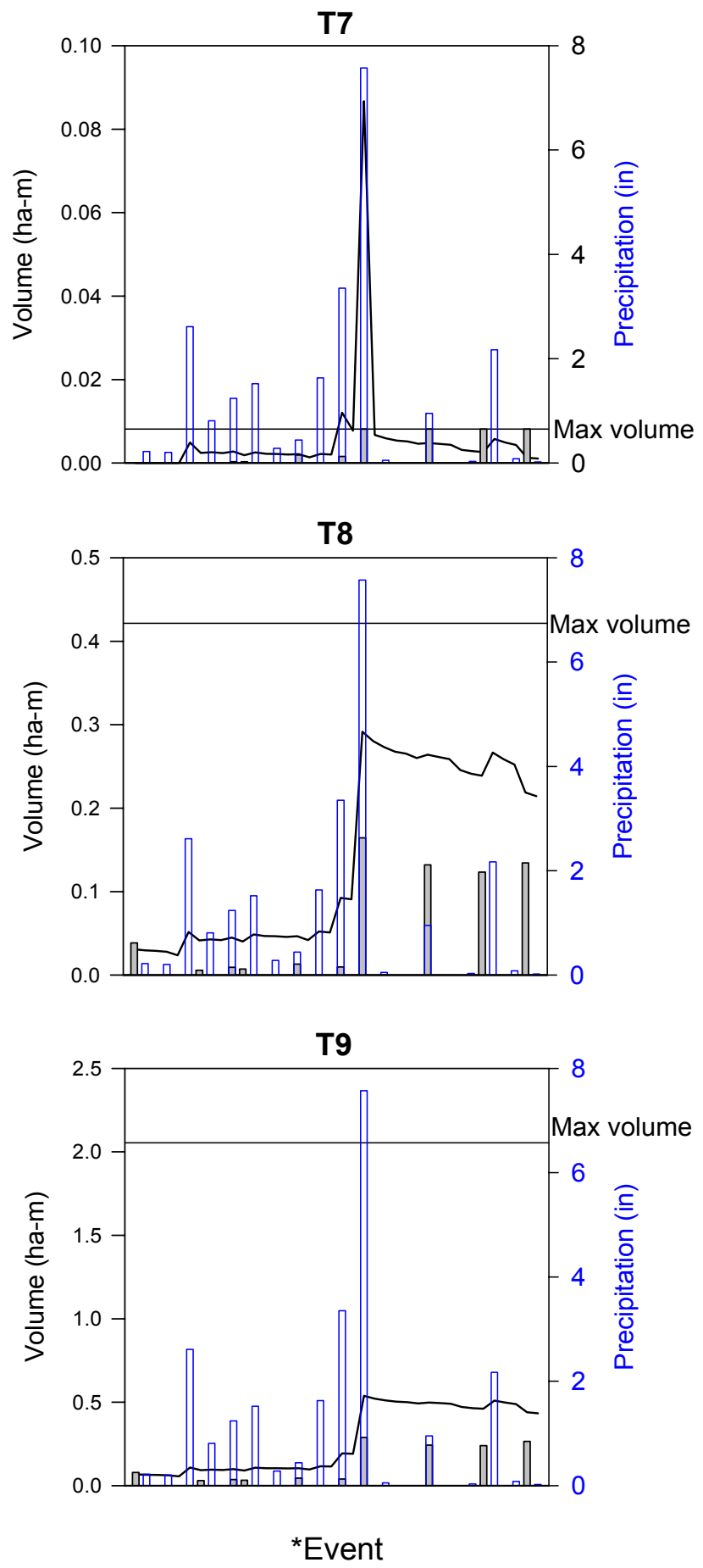

*Event $=1-38($ see table 3$)$

Figure 13. Simulation model calibration for the Cottonwood Lake study area wetlands for the time period of April 14 to September 21, 1993. A, P1, P2, P3, P4, P6, and P7; B, P8, T2, T3, T4, T5, and T6; and C, T7, T8, and T9.-Continued 
Results from the calibration suggested that mean differences in predicted and actual volumes were slightly greater in semipermanent wetlands $(0.13$ ha-m, $\mathrm{SE}=0.02)$ than in seasonal (0.03 ha-m, SE $=0.006)$. These differences, however, are proportionally greater in the seasonal wetlands since the actual volumes are much smaller. This initial calibration suggests that the model performed well and satisfactorily calculated changes in wetland water storage.

\section{Conclusion}

The overall goal of this study was to develop a simple model to simulate changes in wetland water storage for specific precipitation events. Prerequisites of this model included that it could be run by using simple yet widely available data and that the model could account for changes in land use that influence surface water inputs. The model we developed met these requirements and provided reasonably good estimates of changes in wetland water storage; however, additional calibration and testing is necessary to understand how the model will perform over a range of precipitation events. Furthermore, results suggest that future research should explore whether volume and interception area predictive models should be segregated by wetland classification or size classes since the model did not provide equivalent results among wetland classes. Correspondingly, relationships among catchment slope lengths and grades and catchment runoff should be explored. For example, a small wetland surrounded by a large, relatively flat catchment may not receive surface runoff from the entire catchment area, whereas a large wetland surrounded by a proportionally smaller catchment with steep slopes may receive runoff from the entire catchment.

For simplicity, our model was calibrated by using summer precipitation events. The model likely will need to be modified to simulate springtime snowmelt events. The surface runoff curves applied in our model were not developed to estimate runoff from frozen soils. Additionally, our calibration tests did not include wetlands that were in croplands; rather, calibrations were performed on wetlands in grasslands. Although not tested, the model is designed to account for differences in land use. Furthermore, obtaining detailed information to calculate daily evapotranspiration rates would likely improve model performance. With appropriate calibration and testing, this model should have wide applicability as a decision support tool to evaluate the effects of various wetland and land use restoration scenarios designed to provide a broad suite of ecological services, including flood water attenuation.

\section{Chapter C: Application of the Wetland Water Storage Simulation Model to the Upper Mustinka Subbasin}

\section{Overview}

The overall goal of this study was to demonstrate the application of models developed in chapters A and B by simulating the potential of wetlands to intercept, process, and store water in the upper Mustinka subbasin, Grant County, Minn. We simulated wetland water storage increases that would result from restoring 25 and 50 percent of the farmed and drained wetlands in the upper Mustinka subbasin. The model simulations were performed during the growing season (May-October) for relatively wet (1993; $0.67 \mathrm{~m}$ of precipitation) and dry (1987; $0.32 \mathrm{~m}$ of precipitation) years. Model results indicated that the 25 percent restoration scenario would increase water storage by $27-32$ percent and that a 50 percent scenario would increase storage by 53-63 percent. Additionally, we estimated that wetlands in the upper Mustinka subbasin have potential to store 11.57-20.98 percent of the total precipitation that fell there (a land area of 52,758 ha). Our simulation results indicated that there is considerable potential to enhance water storage in the upper Mustinka subbasin; however, evaluation and calibration of the model are necessary before simulation results are deemed reliable for use in management decisions and planning.

\section{Methods}

\section{Study Area}

We applied the simulation model developed in chapter B to existing depressional and potentially restorable wetlands within the upper Mustinka subbasin (fig. 3). Grant County is located in the eastern portion of the Glaciated Plains physiographic region in the southeast reach of the Red River drainage basin (fig. 2). The upper Mustinka subbasin encompasses 52,758 ha, and based on the National Wetlands Inventory (NWI) and RWWG (2002) databases, it contains 2,060 existing depressional wetlands totaling 2,397 ha and 6,161 potentially restorable wetlands totaling 2,819 ha. 


\section{Data Input and Sources}

Precipitation data used for the simulation was obtained for Elbow Lake, Minn., which is centrally located in the upper Mustinka subbasin. The daily evapotranspiration rate was set at $0.358 \mathrm{~cm} \mathrm{~d}^{-1}$ (Parkhurst and others, 1998). Wetland area of existing and potentially restorable wetlands was determined by using NWI and RWWG databases. Maximum wetland storage volume and interception area of each basin was estimated by using equations presented in table 1 and procedures described in chapter A. All potentially restorable wetlands mapped by the RWWG were considered drained and given a cropland land use category. For existing wetlands mapped by the NWI, we determined land use (i.e., cropland or grassland) by using the 1992 National Land Cover Dataset (http://landcover.usgs. gov/). Hydrologic soil group and surface runoff curve numbers for wetland and catchment areas were determined by following procedures described in chapter B and appendix 1 . The following details are provided: for wetlands classified as farmed, catchment areas (figs. 4 and 12) were assigned the runoff curve number 81 (land use = row cropping (straight), hydrologic soil group $=\mathrm{B}, \mathrm{AMC}=\mathrm{II}$, hydrologic condition = poor); the nonponded areas (fig. 12) of the wetland basin were assigned the runoff curve number 91 (land use $=$ row cropping (straight), hydrologic soil group = D, AMC = II, hydrologic condition $=$ poor). Wetlands classified as grass were assigned the runoff curve number 58 for the catchment (land use $=$ meadow, hydrologic soil group $=\mathrm{B}, \mathrm{AMC}=\mathrm{II}$, hydrologic condition $=$ good) and 78 for the nonponded portion of the wetland basin (land use $=$ meadow, hydrologic soil group $=\mathrm{D}$, $\mathrm{AMC}=\mathrm{II}$, hydrologic condition $=$ good). For all wetlands, the ponded portion of the wetland received 100 percent of the precipitation.

\section{Simulation Period}

The model simulation was performed during the growing season (May-October) for relatively wet (1993; $0.67 \mathrm{~m}$ of precipitation) and dry (1987; $0.32 \mathrm{~m}$ of precipitation) years. Precipitation was treated as depositing uniformly over the entire study area. For the simulation, precipitation data were grouped by event, defined as consecutive days with or without precipitation (see chapter B). Appendixes 6 and 7 provide example SAS programs for the creation of the 1987 input data set and the 1987 model simulation for a 25 percent restoration scenario.

\section{Restoration Scenario}

We set the restoration scenario (i.e., percent of farmed wetlands (based on total number of wetlands) restored) at 0 , 25 , and 50 percent. Wetlands restored were randomly selected, and the sample was constrained to wetlands between 0.5 and 20 ha. The minimum restoration size cutoff was applied because restoration of a large number of small wetlands is not likely to be cost effective, whereas the maximum cutoff was set based on the limitations associated with applying volume and interception area estimators to wetlands larger than the model range (see chapter A). Prior to restoration, wetlands obtained from the RWWG database were treated as farmed and drained with no water storage. If selected for restoration, they were treated as hydrologically intact (i.e., store water) and in grass. In contrast, all NWI wetlands were hydrologically intact with a land use of grass or farmed. Hence, in this case, restoration of a farmed wetland consisted of converting the land use to grass. At the start of both simulation periods (i.e., May) we assumed that wetlands were 50 percent full because of water remaining from the previous year and inputs from springtime precipitation and runoff.

\section{Results and Discussion}

Based on simulation results (table 4), a 25 percent restoration scenario would increase water storage by $27-32$ percent, and a 50 percent restoration scenario would increase storage by 53-63 percent; the higher percent storage increases within scenarios occurred during the 1993 simulation period. Most gains in storage were associated with the restoration of drained wetlands (50 percent scenario increase $=1,187$ to 2,330 ha-m), whereas only moderate increases in storage were associated when converting farmed but hydrologically intact wetlands to grass (50 percent scenario $=12$ to 225 ha-m (table 4$)$ ). Assuming that the precipitation was uniform across the study area $(52,758 \mathrm{ha})$ for the simulation time periods $(0.32 \mathrm{~m}$ in $1987 ; 0.67 \mathrm{~m}$ in 1993), depressional wetlands stored from 11.57 to 20.98 percent of the precipitation that fell in the upper Mustinka subbasin (table 5). These simulations suggest that there is considerable potential for existing and potentially restorable wetlands to intercept and store water in the upper Mustinka subbasin. For our simulation we treated wetlands as being 50 percent full at the start of each simulation. Hence, we did not simulate maximum storage potential, and estimates of water storage are likely conservative since wetlands typically draw down in the fall and provide increased storage in the spring.

\section{Conclusion}

The goal of this study was to evaluate the application of models developed in chapters A and B by simulating the potential of wetlands to intercept, process, and store water in the upper Mustinka subbasin; our simulation results indicated that there is considerable potential to enhance water storage there. Results of our model simulations could provide a basis for understanding how restoring wetlands may increase water storage in a watershed of interest; however, evaluation and calibration of the model is always necessary before simulation results are deemed reliable for use in management decisions and planning. As indicated in chapter B, the wetland water storage simulation model requires calibration within the 
Table 4. Results from model simulations performed on National Wetlands Inventory (NWI) and Restorable Wetlands Working Group (RWWG) wetland data for the upper Mustinka subbasin of Grant County, Minn., for the growing seasons of 1987 and 1993. Precipitation totals for the May-0ctober time period were $0.32 \mathrm{~m}$ (1987) and $0.67 \mathrm{~m}$ (1993).

\begin{tabular}{|c|c|c|c|c|c|c|c|c|c|c|}
\hline \multirow{3}{*}{$\begin{array}{l}\text { Restoration } \\
\text { scenario }\end{array}$} & \multirow{3}{*}{ Source } & \multirow{3}{*}{$\begin{array}{l}\text { Land } \\
\text { use }\end{array}$} & \multicolumn{4}{|c|}{ Wetland area ${ }^{4}$} & \multirow{2}{*}{\multicolumn{2}{|c|}{$\begin{array}{c}\text { May-Oct. } 1987 \\
\text { volume }^{4}\end{array}$}} & \multirow{2}{*}{\multicolumn{2}{|c|}{$\begin{array}{c}\text { May-Oct. } 1993 \\
\text { volume }^{4}\end{array}$}} \\
\hline & & & \multirow{2}{*}{ Mean } & \multirow{2}{*}{ Min } & \multirow{2}{*}{ Max } & \multirow{2}{*}{$\mathrm{n}$} & & & & \\
\hline & & & & & & & Stored & Spilled & Stored & Spilled \\
\hline${ }^{1} 0 \%$ & NWI & FARM & 0.61 & 0.002 & 17.02 & 1,551 & $1,393.36$ & 24.62 & $2,305.37$ & 711.36 \\
\hline${ }^{1} 0 \%$ & NWI & GRASS & 1.94 & .016 & 19.99 & 482 & 891.07 & 0 & $1,780.98$ & 114.76 \\
\hline${ }^{2} 25 \%$ & NWI & FARM & .62 & .006 & 14.63 & 1,147 & $1,042.09$ & 18.11 & $1,719.86$ & 535.69 \\
\hline${ }^{2} 25 \%$ & NWI & GRASS & 1.33 & .002 & 19.99 & 886 & $1,248.86$ & .0001 & $2,478.68$ & 178.24 \\
\hline $225 \%$ & RWWG & GRASS & 1.99 & .501 & 19.77 & 286 & 599.11 & 0 & $1,178.81$ & 95.79 \\
\hline${ }^{3} 50 \%$ & NWI & FARM & .63 & .006 & 14.6327 & 765 & 697.09 & 12.27 & $1,154.03$ & 355.12 \\
\hline${ }^{3} 50 \%$ & NWI & GRASS & 1.11 & .002 & 19.99 & 1,268 & $1,599.70$ & .0001 & $3,158.31$ & 245.02 \\
\hline${ }^{3} 50 \%$ & RWWG & GRASS & 1.91 & .501 & 19.86 & 571 & $1,187.31$ & 0 & $2,330.89$ & 195.10 \\
\hline
\end{tabular}

${ }^{1}$ The $0 \%$ restoration scenario represents existing water storage (i.e., all NWI wetlands; no RWWG drained wetlands).

${ }^{2} 25 \%$ of the RWWG wetlands $>0.5$ ha are treated as hydrologically intact (restored) with the associated catchments planted to grass; the NWI wetlands classified as grass consist of existing NWI wetlands (grass) as well as the $25 \%$ of those NWI wetlands previously classified as farmed that are now considered restored (i.e., catchments planted to grass). The NWI wetlands classified as farmed represent the $75 \%$ that were not restored.

${ }^{3} 50 \%$ of the RWWG wetlands $>0.5$ ha are treated as hydrologically intact (restored) with the associated catchments planted to grass; the NWI wetlands classified as grass consist of existing NWI wetlands (grass) as well as the $50 \%$ of those NWI wetlands previously classified as farmed that are now considered restored (i.e., catchments planted to grass). The NWI wetlands classified as farmed represent the $50 \%$ that were not restored.

${ }^{4}$ Wetland areas are presented in hectares; volumes are presented in hectare-meters.

Table 5. Percent of total precipitation stored by depressional wetlands in the upper Mustinka subbasin of Grant County, Minn.

[NWI, National Wetlands Inventory; RWWG, Restorable Wetlands Working Group]

\begin{tabular}{lllcrc}
\hline $\begin{array}{c}\text { Restoration } \\
\text { scenario }\end{array}$ & Source & Land use & $\begin{array}{c}\text { \% of total } \\
\text { precipitation } \\
\text { stored }\end{array}$ & $\begin{array}{c}\text { \% of total } \\
\text { precipitation } \\
\text { stored }\end{array}$ \\
\hline${ }^{1} 0 \%$ & NWI & FARM & 8.39 & 6.53 \\
${ }^{1} 0 \%$ & NWI & GRASS & $\underline{5.37}$ & $\underline{\mathbf{1 9 9 3}}$ \\
& & & $\mathbf{1 3 . 7 6}$ & $\mathbf{1 1 . 5 7}$ \\
${ }^{2} 25 \%$ & NWI & FARM & 6.28 & 4.87 \\
${ }^{3} 25 \%$ & NWI & GRASS & 7.52 & 7.02 \\
${ }^{4} 25 \%$ & RWWG & GRASS & $\underline{3.61}$ & $\underline{3.34}$ \\
& & & $\mathbf{1 7 . 4 1}$ & $\mathbf{1 5 . 2 2}$ \\
${ }^{5} 50 \%$ & NWI & FARM & 4.20 & 3.27 \\
${ }^{6} 50 \%$ & NWI & GRASS & 9.63 & 8.94 \\
${ }^{7} 50 \%$ & RWWG & GRASS & $\underline{7.15}$ & $\underline{6.60}$ \\
& & & $\mathbf{2 0 . 9 8}$ & $\mathbf{1 8 . 8 1}$ \\
\hline
\end{tabular}

\footnotetext{
${ }^{1}$ All depressional NWI wetlands classified as farmed and grass.

${ }^{2} 75 \%$ of NWI farmed wetlands.

${ }^{3} 100 \%$ of NWI grass wetlands $+25 \%$ of restored NWI wetlands.

${ }^{4} 25 \%$ of RWWG wetlands $>0.5$ ha.

$550 \%$ of NWI farmed wetlands.

${ }^{6} 100 \%$ of NWI grass wetlands $+50 \%$ of restored NWI wetlands.

${ }^{7} 50 \%$ of RWWG wetlands $>0.5$ ha.
} 
watershed of interest. Hence, a limitation of our results is that we did not calibrate the model for the upper Mustinka subbasin.

As demonstrated in this study, simulating various restoration scenarios provides useful information to guide land management decisions. Many of the variables that we included to perform simulations are easily obtained from available databases. This model includes many factors (e.g., land use, catchment area, physiographic region) that have previously been overlooked by modelers. In our study we made no attempt to relate potential storage of existing and restorable wetlands to the impacts of flooding or to analyze the direct impacts of wetland drainage. Rather, the purpose of this study was to develop and improve methods to estimate and simulate potential water storage.

\section{Acknowledgments}

Funding for this project was provided by the U.S. Geological Survey and U.S. Fish and Wildlife Service Science Support Program. For their assistance and cooperation with logistics and fieldwork, we thank Lynn Foss, Donald Kirby, and Robert Koltes. We also thank the private landowners for access to land. We wish to thank the following people for review of this report: Diane Eckles, Laurie Fairchild, Phil Gerla, Rex Johnson, James LaBaugh, Wesley Newton, and Kevin Vining. Additionally, we thank the Restorable Wetlands Working Group for providing spatial wetland data and Deb Buhl for statistical assistance.

\section{References Cited}

Bell, A., Eckhardt, D., and Pucherelli, M., 1999, Wetlands inventory and drained wetlands water storage capacity estimation for the St. Joe-Calio Coulee subbasin of the greater Devils Lake basin, North Dakota: Denver, U.S. Department of the Interior, Bureau of Reclamation, Technical Memorandum No. 8260-99-02.

Bengtson, M.L., and Padmanabhan, G., 1999, Hydrologic model for assessing the influence of wetlands on flood hydrographs in the Red River Basin-development and application: Fargo, North Dakota Water Research Institute, North Dakota State University, report submitted to the International Joint Commission Red River Task Force.

Best, R.G., 1978, Utilization of color-infrared aerial photography to characterize prairie potholes, in PECORA IV, Proceedings of the Symposium on Application of Remote Sensing Data to Wildlife Management: Sioux Falls, S. Dak., National Wildlife Federation, Scientific and Technical Series 3, p. 180-187.
Best, R.G., and Moore, D.G., 1979, Landsat interpretation of prairie lakes and wetlands of eastern South Dakota, in Satellite Hydrology, Proceedings of the Fifth Annual William T. Pecora Memorial Symposium on Remote Sensing: American Water Resources Association Technical Publication Series TPS 81-1, p. 499-506.

Bluemle, J.P., 2000, The face of North Dakota-The geologic story ( $3 \mathrm{~d}$ ed.): Grand Forks, North Dakota Geological Survey, Educational Series 26.

Brun, L.J., Richardson, J.W., Enz, J.W., and Larsen, J.K., 1981, Stream flow changes in the southern Red River valley of North Dakota: North Dakota Farm Research Bulletin, v. 38 , p. 11-14.

Dahl, T.E., 1990, Wetland losses in the United States, 1780's to 1980's: Washington, D.C., U.S. Department of the Interior, Fish and Wildlife Service.

Dahl, T.E., and Johnson, C.E., 1991, Status and trends of wetlands in the coterminous United States, mid-1970's to mid1980's: Washington, D.C., U.S. Department of the Interior, Fish and Wildlife Service.

Gleason, R.A., and Tangen, B.A., 2006, Floodwater storage, in Gleason, R.A., Laubhan, M.K., and Euliss, N.H., Jr., (eds.), Ecosystem services derived from wetland conservation practices in the United States Prairie Pothole Region with an emphasis on USDA Conservation Reserve and Wetland Reserve Programs: U.S. Geological Survey, Biological Resources Discipline, Scientific Investigations Report, submitted 2006.

Haan, C.T., and Johnson, H.P., 1967, Geometrical properties of depressions in north-central Iowa: Iowa State Journal of Science, v. 42, p. 149-160.

Hubbard, D.E., 1982, Surface area-volume relationship of wetland basins in the interior of the Coteau Des Prairies, in Proceedings of the South Dakota Academy of Sciences, v. 61, p. $154-158$.

Manale, A., 2000, Flood and water quality management through targeted, temporary restoration of landscape functions - paying upland farmers to control runoff: Journal of Soil and Water Conservation, v. 55, p. 285-295.

Miller, J.E., and Frink, D.L., 1984, Changes in flood response of the Red River of the North basin, North DakotaMinnesota: U.S. Geological Survey, Water Resources Division, Water-Supply Paper 2243.

Miller, M.W., and Nudds, T.D., 1995, Prairie landscape change and flooding in the Mississippi River Valley: Conservation Biology, v. 10, p. 847-853. 
Moore, I.D., and Larson, C.L., 1979, Effects of drainage projects on surface runoff from small depressional watersheds in the north central region: University of Minnesota, Water Resources Research Center Bulletin 99.

Parkhurst, R.S., Winter, T.C., Rosenberry, D.O., and Sturrock, A.M., 1998, Evaporation from a small prairie wetland in the Cottonwood Lake area, North Dakota—an energy-budget study: Wetlands, v. 18, p. 272-287.

Restorable Wetlands Working Group, 2002, Minnesota restorable wetlands: accessed 2002 at http://prairie.ducks.org/ index.cfm? \&page=minnesota/restorablewetlands/home.htm

Simonovic, S.P., and Juliano, K.M., 2001, Role of wetlands during low frequency flooding events: Canadian Water Resources Journal, v. 26, p. 377-397.

Stewart, R.E., and Kantrud, H.A., 1971, Classification of natural ponds and lakes in the glaciated prairie region: Washington, D.C., U.S. Department of the Interior, Fish and Wildlife Service publication 92.

Tiner, R.W., Jr., 1984, Wetlands of the United States-current status and recent trends: Washington, D.C., U.S. Fish and Wildlife Service, U.S. Government Printing Office.

Tripod Data Systems, Inc., 1997, Foresight for Windows: Corvallis, Oreg., Tripod Data Systems, Inc.
SAS Institute, Inc., 2001, SAS software release 8.02: Cary, N.C., SAS Institute, Inc.

Vining, K.C., 2002, Simulation of streamflow and wetland storage, Starkweather Coulee subbasin, North Dakota, water years 1981-98: U.S. Geological Survey Water-Resources Investigations Report 02-4113.

Wiens, L.H., 2001, Surface area volume relationship for prairie wetlands in the upper Assiniboine River basin, Saskatchewan: Canadian Water Resources Journal, v. 26, p. 503-513.

Winter, T.C., 1989, Hydrologic studies of wetlands in the northern prairie, in van Der Valk, A. (ed.), Northern prairie wetlands: Ames, Iowa State University Press, p. 16-54.

Winter, T.C., 2003, Hydrological, chemical, and biological characteristics of a prairie pothole wetland complex under highly variable climate conditions - the Cottonwood Lake Area, east-central North Dakota: U.S. Geological Survey Professional Paper 1675.

Winter, T.C., and Rosenberry, D.O., 1995, The interaction of ground water with prairie pothole wetlands in the Cottonwood Lake area, east central North Dakota, 1979-1990: Wetlands, v. 15, p. 193-211. 
Appendixes 1-7 


\section{Appendix 1. Acquiring input data, defining model scenarios, obtaining runoff curve numbers, creating input database, and interpreting model simulations.}

The model uses simple input variables to simulate wetland hydrology. Proficiency with the statistical software program SAS (SAS Institute, Inc., 2001) is required to modify and run the attached programming code. This appendix describes the model and defines the input and model variables. The following appendixes provide the SAS code necessary to create the input database and run the model.

Step 1. Obtain precipitation data and determine daily evapotranspiration, land use and soil types, restoration and starting volume scenarios, etc.

A. Obtain daily precipitation, wetland (e.g., National Wetlands Inventory (NWI), Restorable Wetlands Working Group (RWWG)), soil, and land use information for the area of interest. The soil and land use information will be used to determine the Natural Resources Conservation Service (NRCS) curve numbers.

B. If working in the Prairie Pothole Region, all necessary models (i.e., volume, area) are provided in this report; models may also be obtained from additional sources available in the literature (e.g., Best, 1978; Hubbard, 1982; Wiens, 2001).

C. Determine approximate mean daily evapotranspiration rate for depressional wetlands of the region.

D. Determine the starting volume scenario.

a. Estimation of the starting volume scenario can be based on precipitation, snowfall, or general observations. For example, during extreme drought when a majority of wetlands are dry, the starting scenario would be 100 percent (i.e., 100 percent of the maximum volume is available for water storage). Similarly, during an extremely wet period the scenario would be 0 percent (i.e., wetlands are full), and during an average period the scenario would be 50 percent (i.e., wetlands are 50 percent full).

b. Estimation of the starting volume scenario can be based on data from a series of instrumented wetlands. For example, one could measure the spring water volume for a representative set of wetlands in the region of interest and use the mean volume (e.g., 25 percent, 50 percent, etc.) for the starting scenario. Similarly, one could measure water volumes in the fall and create a springtime runoff event by using precipitation data (from snowfall); however, this type of "spring dump" would require information related to runoff over frozen soils and wintertime evaporation rates.

E. A restoration scenario can also be added to the model. This act would simply entail randomly selecting a percentage of wetlands in the region of interest to restore (e.g., 1 percent, 10 percent, 50 percent) or selecting certain areas of interest. A restoration scenario can also include wetland size. For example, it is likely not practical to restore large numbers of very small wetlands to mitigate flooding. As part of the restoration scenario, one may want to consider larger wetlands that store more water per restoration and would be more cost effective.

F. Determine the proper runoff curve numbers for specific land use and soil combinations for each zone (fig. 12) in the model. Because of general soil characteristics, the model incorporates unique curve numbers for the catchment area $\left(\mathrm{CATCH} \_\mathrm{A}\right)$ and the nonponded portion of the wetland area $\left(\mathrm{CATCH} \_\mathrm{A} \_2\right)$.

a. Information for determining runoff by using curve numbers is available from the NRCS in the National Engineering Handbook (NEH) at the following Web site: ftp://ftp.wcc.nrcs.usda.gov/downloads/hydrology_hydraulics/ neh630\%.

b. NEH chapter 10 describes the curve number process and provides information on land use and treatment categories, hydrologic soil groups, and hydrologic condition. The general procedure is as follows:

$$
Q=(P-0.2 S)^{2} /(P+0.8 S)
$$

where

\footnotetext{
$Q \quad=$ accumulated direct runoff; direct flow volume expressed as a depth,

$P \quad=$ accumulated rainfall (potential maximum runoff), and

$S=$ surrogate for initial abstraction; it is the potential maximum retention; the curve number is used to aid in the estimation of $S$
} 


$$
S=(1000 / C N)-10
$$

where

$C N=$ curve number

Steps to determine curve number $(C N)$ :

1. determine hydrologic soil group

2. determine land use and treatment (practice) categories

3. determine hydrologic condition category

c. Calculate the minimum amount of precipitation required to generate runoff for each curve number. This computation can be done by simply plotting the results from the runoff equation for a range of precipitation amounts and identifying where $Q=0$.

Step 2. Create input database and run model.

A. Create SAS database (by using SAS code in appendix 2) containing the variables listed and described in table 1-1. Appendix 4 describes, in detail, the SAS code in appendix 2. Appendix 6 provides example SAS code used to create the input database for the 1987 simulation (see chapter 3).

B. Using database created in step 2A, run the model by using the SAS program in appendix 3. Table 1-2 lists and describes the model variables. Appendix 5 describes, in detail, the SAS code in appendix 3. Appendix 7 provides example SAS program used for 1987 (25 percent restoration scenario) simulation model (see chapter C).

Step 3. Interpretation of simulation.

Volume Stored

The variable VOL_STORE (volume stored) is the predicted wetland volume for a specific time period (event); it can be used to graph wetland volume over time or determine wetland volume for a specific period. Since this variable is additive, simply summing it will not provide the total volume stored for the simulation period.

To determine the total volume stored for a simulation, multiply the sum of the individual interception areas by the total precipitation (potential storage), then subtract the sum of the volume spilled variable (VOL_SPILL). The volume stored for a simulation period is equal to the potential storage (i.e., precipitation $\times$ interception area) minus the volume spilled (VOL_SPILL). In this method, the volume stored includes water lost to evaporation as well as water that infiltrated into the catchment soils.

\section{Volume Spilled}

To determine the amount of water that wetlands did not store (i.e., spill volume), simply sum the variable VOL_SPILL; it is not additive.

Table 1-1. Definition of input database variables for simulation model.

[NWI, National Wetlands Inventory; RWWG, Restorable Wetlands Working Group; RWI, Restorable Wetlands Inventory]

\begin{tabular}{llc}
\hline \multicolumn{1}{c}{ Abbreviation } & & \multicolumn{1}{c}{ Definition } \\
\hline AREA_HA & wetland area obtained from NWI, RWWG & Units \\
CATCH_A & wetland catchment area (INT_A - AREA_HA) & ha \\
DAY & day of month & ha \\
ET_M & daily estimate of evapotranspiration $\times$ EVENT_DAYS & m \\
EVENT & precipitation event defined as consecutive days with or without measurable precipitation & - \\
EVENT_DAYS & number of days in EVENT & -- \\
INT_A & estimate of wetland interception area from interception area model (table 1) \\
JUL_DATE & Julian date & ha \\
LANDUSE & land use category (e.g., farm, grass) \\
MONTH & month
\end{tabular}


Table 1-1. Definition of input database variables for simulation model._-Continued

[NWI, National Wetlands Inventory; RWWG, Restorable Wetlands Working Group; RWI, Restorable Wetlands Inventory]

\begin{tabular}{|c|c|c|}
\hline Abbreviation & Definition & Units \\
\hline PP2 & $\begin{array}{l}\text { variable in SAS program used to identify whether there was measurable precipitation on the previous day } \\
\text { (PRECIP_2) when creating the EVENT variable }\end{array}$ & -- \\
\hline PRECIP_2 & codes days with and without measurable precipitation & -- \\
\hline PRECIP_M & daily precipitation & $\mathrm{m}$ \\
\hline SAS_DATE & date in SAS format & -- \\
\hline SOURCE & source of wetland data, NWI or RWI (RWWG) & -- \\
\hline START & codes start and nonstart days for model & -- \\
\hline V_SCEN & starting volume scenario, or the average wetland starting volume (as a $\%$ of maximum) for first day of model & $\%$ \\
\hline
\end{tabular}

Table 1-2. Definition of variables created in the wetland hydrology simulation model.

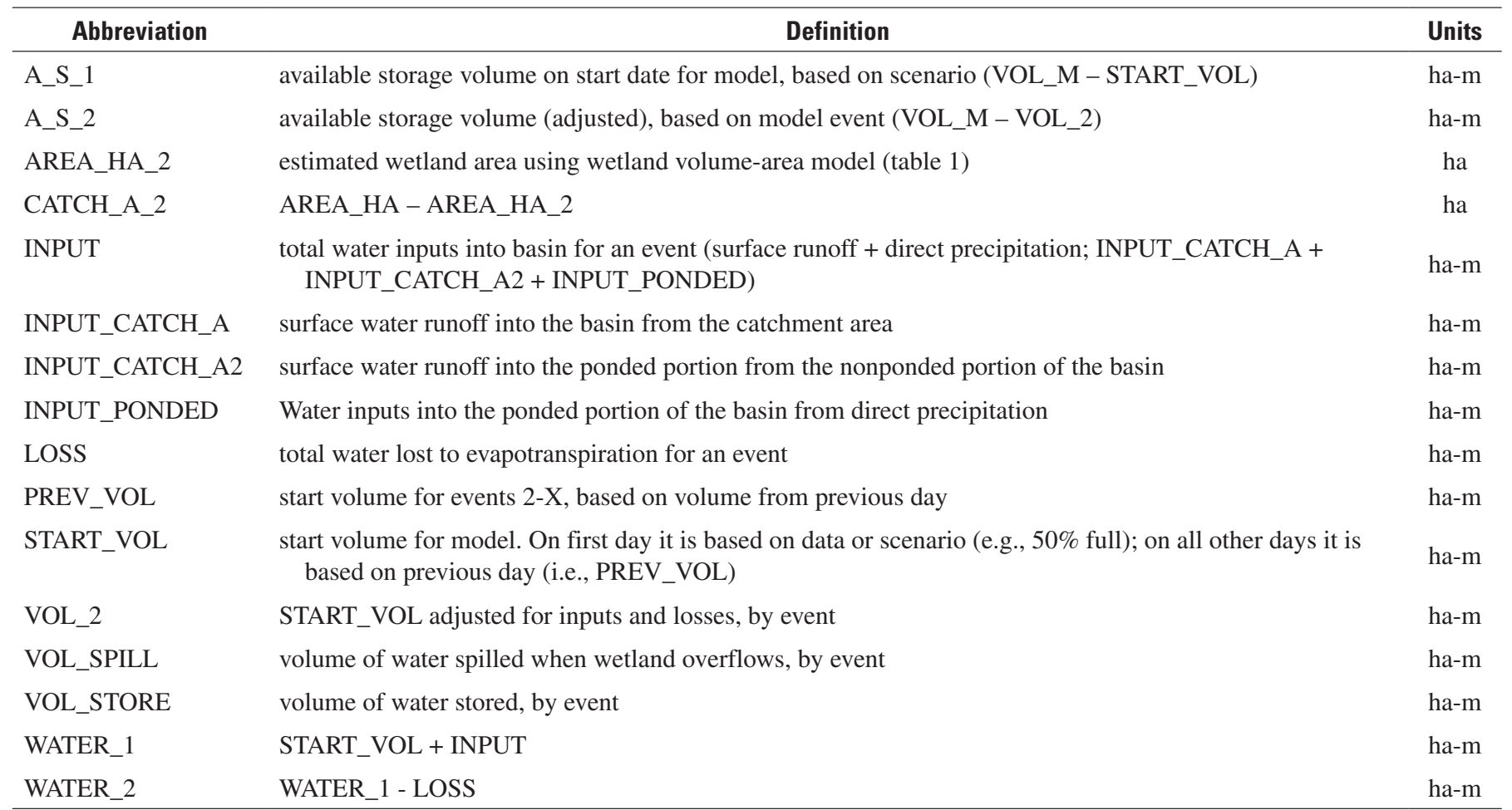




\section{Appendix 2. SAS program to create input database for simulation model (contact the authors with any questions regarding the programming or model input variables).}

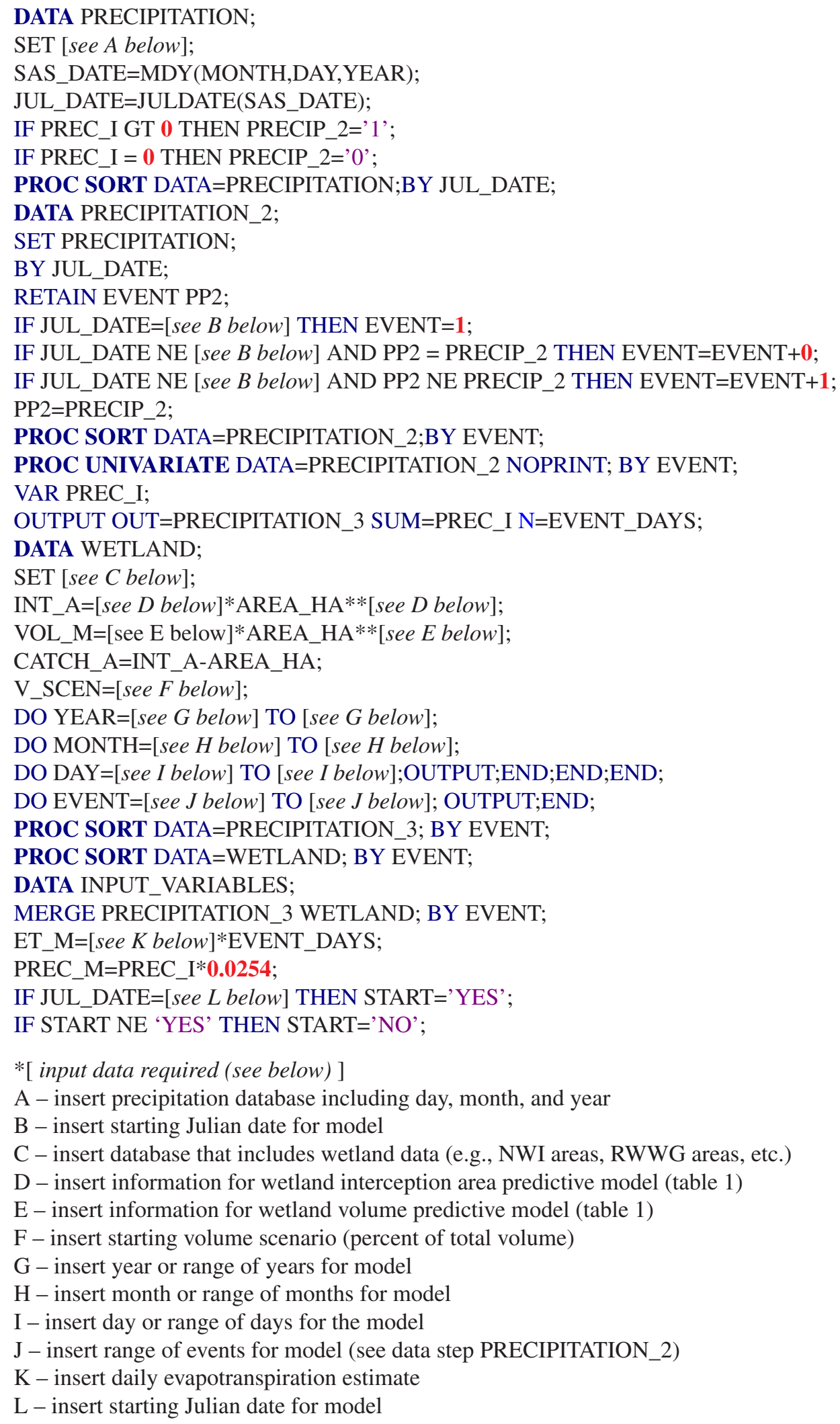




\title{
Appendix 3. SAS program for simulation model (contact the authors with any questions regarding the programming or model variables).
}

\author{
DATA MODEL; \\ SET [see A below]; \\ BY WETLAND; \\ RETAIN PREV_VOL; \\ IF START='YES' THEN START_VOL=VOL_M*V_SCEN; \\ IF START='NO' THEN START_VOL=PREV_VOL; \\ A_S_1=VOL_M-START_VOL; \\ AREA_HA_2 $=[$ see $B$ below $] *$ START_VOL**[see B below $]$; \\ CATCH_A_2=AREA_HA-AREA_HA_2; \\ IF LANDUSE='insert landuse \#1 here' AND PREC_I GT [see C below] THEN INPUT_CATCH_A=(((PREC_I-(0.2* \\ $[$ see D below] $)) * * 2) /($ PREC_I+ $(0.8 *[$ see D below] $)) * 0.0254)) *$ CATCH_A); \\ IF LANDUSE='insert landuse \#1 here' AND PREC_I LE [see C below] THEN INPUT_CATCH_A=0; \\ IF LANDUSE='insert landuse \#1 here'AND PREC_I GT [see C below] THEN INPUT_CATCH_A_2= \\ $\left(((\right.$ PREC_I- $(0.2 *[$ see D below $])) * * 2) /\left(\mathrm{PREC} \_I+(0.8 *[\right.$ see D below $\left.\left.\left.])\right) * 0.0254\right) * \mathrm{CATCH} \_\mathrm{A} \_2\right)$; \\ IF LANDUSE='insert landuse \#1 here AND PREC_I LE [see C below] THEN INPUT_CATCH_A_2=0; \\ IF PREC_I GT 0 THEN INPUT_PONDED=PREC_M*AREA_HA_2; \\ IF PREC_I = 0 THEN INPUT_PONDED=0; \\ IF LANDUSE='insert landuse \#2 here' AND PREC_I GT [see C below] THEN INPUT_CATCH_A=((((PREC_I-(0.2* \\ $[$ see D below] $\left.))^{* * 2) /(\text { PREC_I }+(0.8 *[\text { see D below] }) * 0.0254)}\right) *$ CATCH_A); \\ IF LANDUSE='insert landuse \#2 here' AND PREC_I LE [see C below] THEN INPUT_CATCH_A=0; \\ IF LANDUSE='insert landuse \#2 here'AND PREC_I GT [see C below] THEN INPUT_CATCH_A_2= \\ $\left(((\right.$ PREC_I- $(0.2 *[$ see $D$ below $])) * * 2) /\left(\mathrm{PREC} \_\mathrm{I}+(\mathbf{0 . 8} *[\right.$ see D below $\left.\left.\left.])\right) * 0.0254\right) * \mathrm{CATCH} \_\mathrm{A} \_2\right)$; \\ IF LANDUSE='insert landuse \#2 here AND PREC_I LE [see C below] THEN INPUT_CATCH_A_2=0; \\ INPUT_PONDED=PREC_M*AREA_HA_2; \\ INPUT=INPUT_CATCH_A + INPUT_CATCH_A_2 + INPUT_PONDED; \\ WATER_1=(START_VOL+INPUT); \\ IF WATER_1 GT 0 THEN LOSS=([see B below $] *$ WATER_1**[see B below] $) * E T \_M$; \\ IF WATER_1 LE 0 THEN LOSS=0; \\ IF LOSS LE WATER_1 THEN WATER_2=START_VOL+INPUT-LOSS; \\ IF LOSS GT WATER_1 THEN WATER_2 $=0$; \\ IF WATER_2 GT 0 THEN VOL_2=WATER_2; \\ IF WATER_2 LE 0 THEN VOL_2=0; \\ A_S_2=VOL_M-VOL_2; \\ IF A_S_2 GE 0 THEN VOL_STORE=VOL_2; \\ IF A_S_2 LT 0 THEN VOL_STORE=VOL_M; \\ IF A_S_2 GE 0 THEN VOL_SPILL=0; \\ IF A_S_2 LT 0 THEN VOL_SPILL=ABS(A_S_2); \\ PREV_VOL=VOL_STORE;RUN; \\ *[ input data required (see below) ] \\ A - insert model input data set (see appendix 2) \\ $\mathrm{B}$ - insert information for wetland area predictive model (table 1) \\ $\mathrm{C}$ - insert minimum amount of precipitation (inches) needed to generate runoff (unique for each runoff curve) \\ $\mathrm{D}$ - insert $\mathrm{S}$ value calculated by using runoff curve number (see appendix 1)
}




\section{Appendix 4. Description of SAS code (appendix 2) used to create input database for simulation model.}

DATA PRECIPITATION; names data step

SET [see A below]; sets precipitation input data set

SAS_DATE=MDY(MONTH,DAY,YEAR); formats date for SAS

JUL_DATE=JULDATE(SAS_DATE); creates Julian date variable

IF PREC_I GT 0 THEN PRECIP_2='1'; codes days with precipitation

IF PREC_I = 0 THEN PRECIP_2='0'; codes days with no precipitation

PROC SORT DATA=PRECIPITATION;BY JUL_DATE; sorts data

DATA PRECIPITATION_2; names data step

SET PRECIPITATION; sets input data

BY JUL_DATE; specifies "by" variable

RETAIN EVENT PP2; specifies "retain" variables

IF JUL_DATE=[see $B$ below $]$ THEN EVENT $=1$; sets date for beginning of event \#1

IF JUL_DATE NE [see $B$ below] AND PP2 = PRECIP_2 THEN EVENT=EVENT+0; creates events

IF JUL_DATE NE [see B below] AND PP2 NE PRECIP_2 THEN EVENT=EVENT+1; creates events

PP2=PRECIP_2; creates PP2 variable

PROC SORT DATA=PRECIPITATION_2;BY EVENT; sorts data

PROC UNIVARIATE DATA=PRECIPITATION_2 NOPRINT; BY EVENT;*sums precipitation for each

VAR PREC_I;

*event and creates

OUTPUT OUT=PRECIPITATION_3 SUM=PREC_I N=EVENT_DAYS; $\quad *$ EVENT_DAYS variable

DATA WETLAND; names data step

SET [see $C$ below]; sets input data

INT_A=[see D below]*AREA_HA**[see D below]; uses model from Table 1 to create INT_A variable

VOL_M=[see E below]*AREA_HA**[see E below]; uses model from Table 1 to create V0L_M variable

CATCH_A=INT_A-AREA_HA; creates CATCH_A variable

V_SCEN=[see F below]; creates V_SCEN variable

DO YEAR=[see G below] TO [see G below]; creates YEAR variable (use year(s) in precipitation data set)

DO MONTH=[see H below] TO [see H below]; creates MONTH variable (use month(s) in precipitation data)

DO DAY=[see I below] TO [see I below]; creates DAY variable (use day(s) in precipitation data set)

OUTPUT;END;END;END; ends "DO" statements used to create YEAR, MONTH, DAY variables

DO EVENT=[see J below] TO [see J below]; creates EVENT variable (see PRECIPITATION_3 data set)

OUTPUT;END; ends "DO" statement used to create EVENT variable

PROC SORT DATA=PRECIPITATION_3; BY EVENT; sorts data

PROC SORT DATA=WETLAND; BY EVENT; sorts data

DATA INPUT_VARIABLES; names final input variable data set used in model simulation

MERGE PRECIPITATION_3 WETLAND; BY EVENT; merges data sets created above

ET_M=[see K below $] *$ EVENT_DAYS; creates ET_M variable for each event

PREC_M=PREC_I*0.0254; creates PREC_M variable

IF JUL_DATE=[see L below] THEN START='YES'; codes start date for model

IF START NE 'YES' THEN START='NO'; codes “non-start” days for model

*[ input data required (see below) ]

A - insert precipitation database including day, month, and year

B - insert starting Julian date for model

C - insert database that includes wetland data (e.g., NWI areas, RWWG areas, etc.)

$\mathrm{D}$ - insert information for wetland interception area predictive model (table 1)

E - insert information for wetland volume predictive model (table 1)

$\mathrm{F}$ - insert starting volume scenario (percent of total volume)

$\mathrm{G}$ - insert year or range of years for model

$\mathrm{H}$ - insert month or range of months for model

I - insert day or range of days for the model

$\mathrm{J}$ - insert range of events for model (see data step PRECIPITATION_2)

$\mathrm{K}$ - insert daily evapotranspiration estimate

$\mathrm{L}$ - insert starting Julian date for model 


\section{Appendix 5. Description of SAS code (appendix 3) for simulation model.}

DATA MODEL; names data step

SET [see A below]; sets input database

BY WETLAND; specifies "by" variable

RETAIN PREV_VOL; specifies "retain" variable

IF START='YES' THEN START_VOL=VOL_M*V_SCEN; creates START_VOL for day 1 of model

IF START='NO' THEN START_VOL=PREV_VOL; creates START_VOL for day $2-x$ of model

A_S_1=VOL_M-START_VOL; creates A_S_1 variable

AREA_HA_2=[see B below]*START_VOL**[see B below]; uses model (Table 1) to create AREA_HA_2

CATCH_A_2=AREA_HA-AREA_HA_2; creates CATCH_A_2 variable

The following steps calculates INPUT_CATCH_A, and INPUT_CATCH_A2 for precipitation events that generate surface runoff (each curve number has a minimum amount of precipitation required to generate runoff). INPUT_PONDED and INPUT are calculated for all precipitation events. The code contains the runoff equation (Appendix A) and applies it to the catchment area and the nonponded portion of the wetland basin. This code must be customized for each land use / S-value combination (see Appendix A).

IF LANDUSE='insert landuse \#1 here' AND PREC_I GT [see C below] THEN INPUT_CATCH_A=((((PREC_I-(0.2*

[see D below] $)) * * 2) /($ PREC_I+(0.8*[see D below] $) * 0.0254) *$ CATCH_A $)$;

IF LANDUSE='insert landuse \#1 here' AND PREC_I LE [see C below] THEN INPUT_CATCH_A=0;

IF LANDUSE='insert landuse \#1 here' AND PREC_I GT [see C below] THEN INPUT_CATCH_A_2=((((PREC_I-

$(0.2 *[$ see $D$ below $]) * * 2) /($ PREC_I+(0.8*[see D below $]) * 0.0254) *$ CATCH_A_2);

IF LANDUSE='insert landuse \#1 here' AND PREC_I LE [see C below] THEN INPUT_CATCH_A_2=0;

INPUT_PONDED=PREC_M*AREA_HA_2;

IF LANDUSE='insert landuse \#2 here' AND PREC_I GT [see C below] THEN INPUT_CATCH_A $((($ PREC_I-(0.2*

$[$ see D below $])) * * 2) /($ PREC_I+(0.8*[see D below] $)) * 0.0254) *$ CATCH_A);

IF LANDUSE='insert landuse \#2 here' AND PREC_I LE [see C below] THEN INPUT_CATCH_A=0;

IF LANDUSE='insert landuse \#2 here' AND PREC_I GT [see C below] THEN INPUT_CATCH_A_2((((PREC_I-

$(0.2 *[$ see $D$ below $])) * 2) /($ PREC_I+ $(0.8 *[$ see D below $])) * 0.0254) *$ CATCH_A_2);

IF LANDUSE='insert landuse \#2 here' AND PREC_I LE [see C below] THEN INPUT_CATCH_A_2=0;

IF PREC_I GT 0 THEN INPUT_PONDED=PREC_M*AREA_HA_2;

IF PREC_I = 0 THEN INPUT_PONDED=0;

INPUT=INPUT_CATCH_A + INPUT_CATCH_A_2 + INPUT_PONDED;

WATER_1=(START_VOL+INPUT); creates WATER_1 variable

*The following step calculates LOSS (i.e., loss to evapotranspiration). The ponded wetland area is adjusted (using model from

table 1) according to precipitation inputs; this area is multiplied by ET_M.

IF WATER_1 GT 0 THEN LOSS=([see B below ]*WATER_1**[see B below] $) * E T \_M$;

IF WATER_1 LE 0 THEN LOSS=0;

IF LOSS LE WATER_1 THEN WATER_2=START_VOL+INPUT-LOSS; creates WATER_2 variable

IF LOSS GT WATER_1 THEN WATER_2=0; creates WATER_2 variable

IF WATER_2 GT 0 THEN VOL_2=WATER_2; creates VOL_2 variable

IF WATER_2 LE 0 THEN VOL_2=0; creates VOL_2 variable

A_S_2=VOL_M-VOL_2; creates A_S_2 variable

IF A_S_2 GE 0 THEN VOL_STORE=VOL_2; creates VOL_STORE variable

IF A_S_2 LT 0 THEN VOL_STORE=VOL_M; creates VOL_STORE variable

IF A_S_2 GE 0 THEN VOL_SPILL=0; creates VOL_SPILL variable

IF A_S_2 LT 0 THEN VOL_SPILL=ABS(A_S_2); creates VOL_SPILL variable

PREV_VOL=VOL_STORE;RUN; creates PROV_VOL variable

*[ input data required (see below) ]

A - insert model input data set

B - insert information for wetland area predictive model (table 1)

$\mathrm{C}$ - insert minimum amount of precipitation (inches) needed to generate runoff (unique for each runoff curve)

$\mathrm{D}$ - insert $\mathrm{S}$ value calculated by using runoff curve number 


\section{Appendix 6. SAS program used to create input database for 1987 simulation model.}

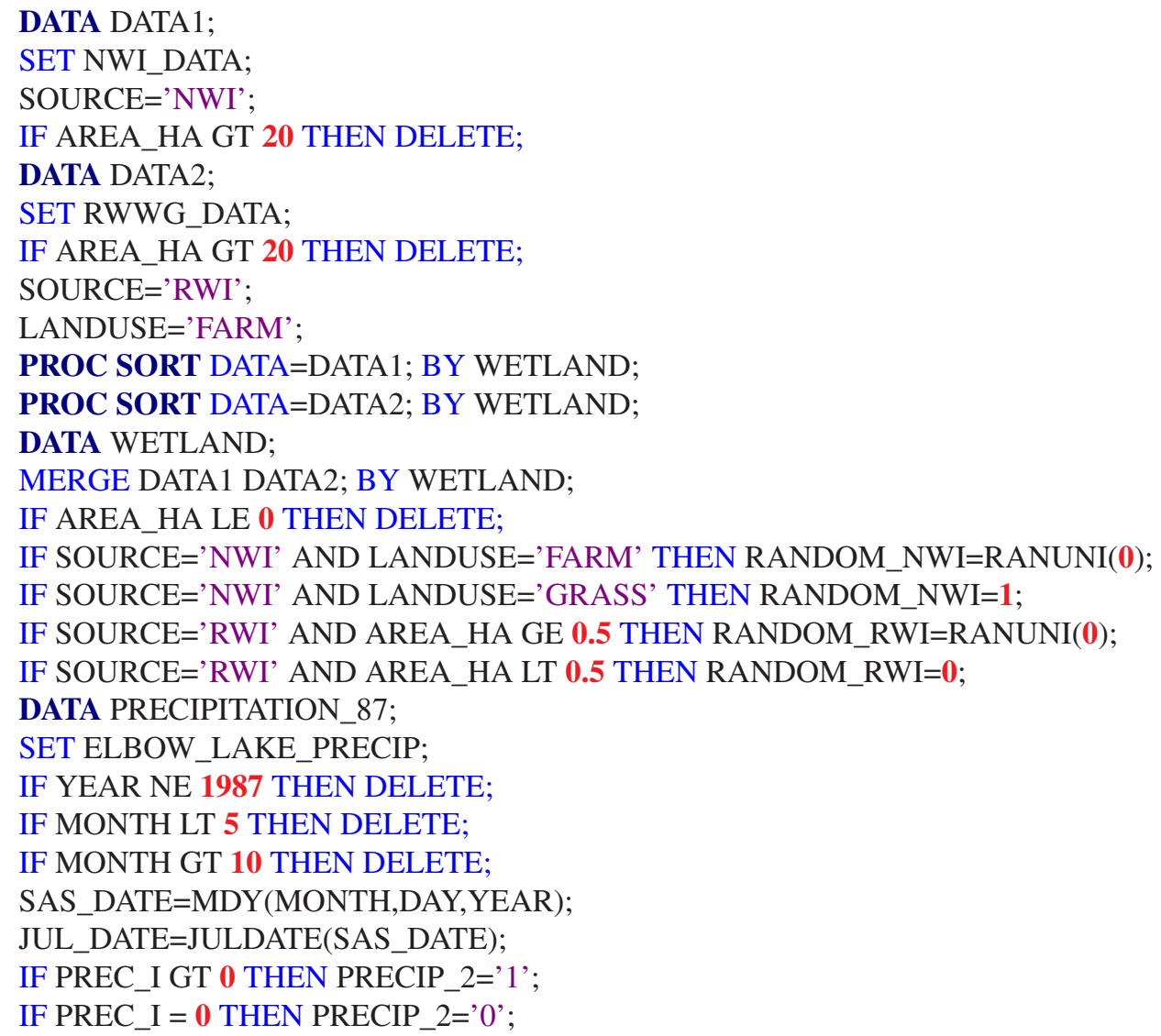


ET_M=0.00358*EVENT_DAYS;

PREC_M=PREC_I*0.0254;

IF EVENT $=1$ THEN START='YES';

IF START NE 'YES' THEN START='NO';

\section{Appendix 7. SAS program for 1987 (25 percent restoration scenario) simulation model.}

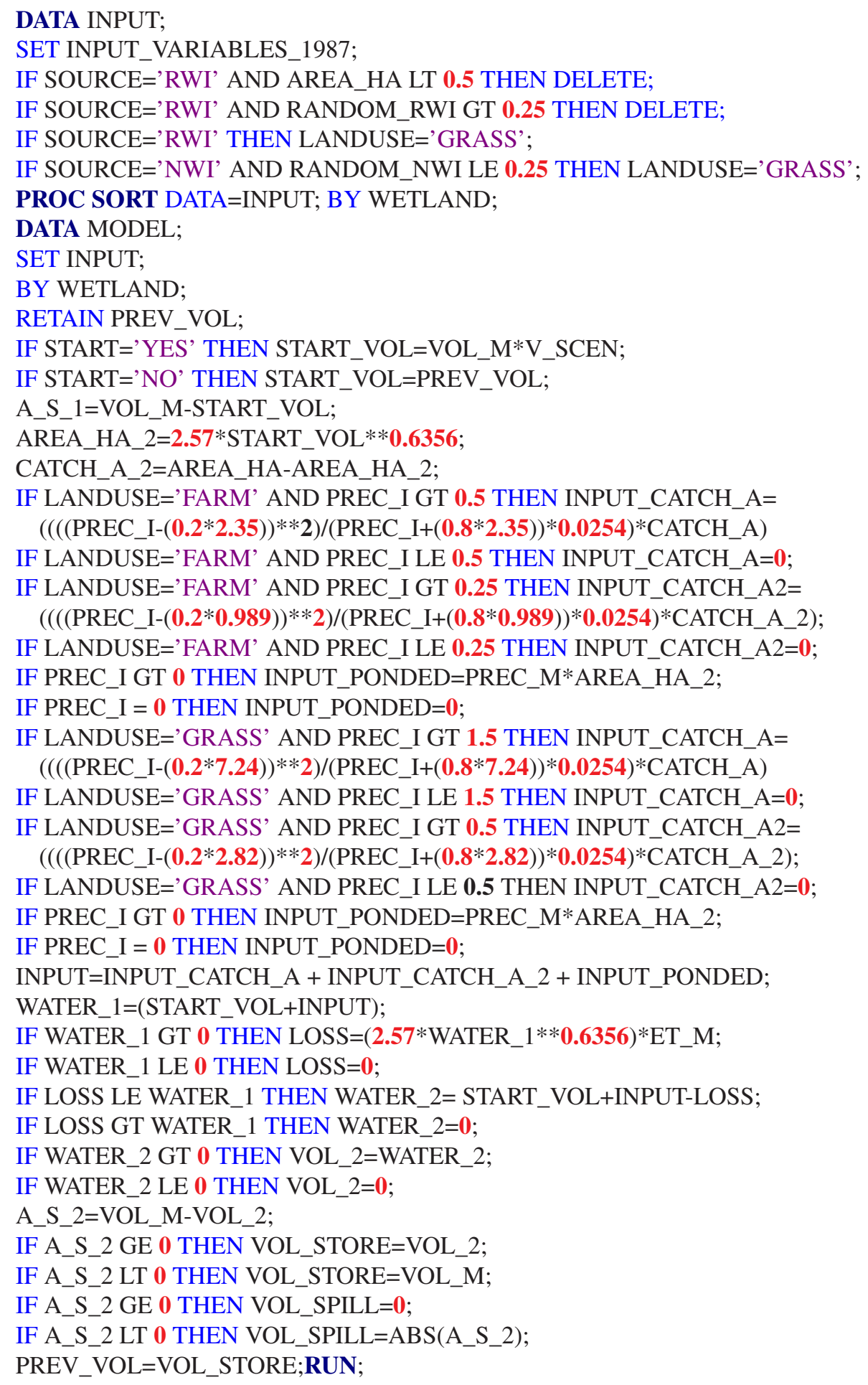


Prepared by the Helena Publishing Service Center

For additional information contact:

Director, Northern Prairie Wildlife Research Center

U.S. Geological Survey

8711 37th Street Southeast

Jamestown, North Dakota 58401

(701) 253-5500

http://www.npwrc.usgs.gov/ 
